\title{
Contribution of NMDA Receptors to Synaptic Function in Rat Hippocampal Interneurons
}

\author{
Sam A. Booker, ${ }^{1,2,3}$ Anna Sumera, ${ }^{1,2,3}$ Peter C. Kind, ${ }^{1,2,3,4}$ and ${ }^{\circ D a v i d ~ J . ~ A . ~ W y l l i e ~}{ }^{1,2,3,4}$ \\ https://doi.org/10.1523/ENEURO.0552-20.2021 \\ ${ }^{1}$ Centre for Discovery Brain Sciences, University of Edinburgh, Edinburgh EH8 9XD, United Kingdom, ${ }^{2}$ Simons \\ Initiative for the Developing Brain, University of Edinburgh, Edinburgh EH8 9XD, United Kingdom, ${ }^{3}$ Patrick Wild \\ Centre, University of Edinburgh, Edinburgh EH8 9XD, United Kingdom, and ${ }^{4}$ Centre for Brain Development and Repair, \\ Institute for Stem Cell Biology and Regenerative Medicine, Bangalore 560065, India
}

\begin{abstract}
The ability of neurons to produce behaviorally relevant activity in the absence of pathology relies on the fine balance of synaptic inhibition to excitation. In the hippocampal CA1 microcircuit, this balance is maintained by a diverse population of inhibitory interneurons that receive largely similar glutamatergic afferents as their target pyramidal cells, with EPSCs generated by both AMPA receptors (AMPARs) and NMDA receptors (NMDARs). In this study, we take advantage of a recently generated GluN2A-null rat model to assess the contribution of GluN2A subunits to glutamatergic synaptic currents in three subclasses of interneuron found in the CA1 region of the hippocampus. For both parvalbumin-positive and somatostatin-positive interneurons, the GluN2A subunit is expressed at glutamatergic synapses and contributes to the EPSC. In contrast, in cholecystokinin (CCK)positive interneurons, the contribution of GluN2A to the EPSC is negligible. Furthermore, synaptic potentiation at glutamatergic synapses on CCK-positive interneurons does not require the activation of GluN2A-containing NMDARs but does rely on the activation of NMDARs containing GluN2B and GluN2D subunits.
\end{abstract}

Key words: hippocampus; interneuron; long-term potentiation; NMDA receptor; receptor subunits; whole-cell patch-clamp

\section{Significance Statement}

NMDA receptors (NMDARs) are ionotropic glutamate receptors that play a critical role in interneuronal communication, and learning and memory. Despite much being known about NMDARs and the role different subunits play in controlling principal cell activity, less is known about their function in inhibitory interneurons. Here, we use a recently developed rat line where the key GluN2A receptor subunit is removed, combined with subunit-specific pharmacology determine the synaptic properties and role of NMDAR subunits in interneuron function. Notably, we show that cholecystokinin-containing interneurons lack synaptic GluN2A and that long-term potentiation at glutamatergic synapses on them is mediated by GluN2D subunits. Our findings have ramifications for the etiology of neuropathological states and basic properties of brain function.

\section{Introduction}

Neuronal networks require finely balanced excitatory glutamatergic and inhibitory GABAergic synaptic transmission to allow learning, memory, and typical brain function. Alterations to this balance may result in autism and intellectual disability (Antoine et al., 2019), epilepsy

Received December 17, 2020; accepted July 3, 2021; First published July 29, 2021.

The authors declare no competing financial interests.
(Sloviter, 1987), schizophrenia (Daskalakis et al., 2002), and depression (Czéh et al., 2015). This balance has been well described in the CA1 of the hippocampus, where local inhibition arises from a heterogeneous population of inhibitory interneurons (INs) forming dense connections with themselves and excitatory pyramidal cells (PyrCs;

Author contributions: S.A.B., P.C.K., and D.J.A.W. designed research; S.A.B. and A.S. performed research; S.A.B., A.S., P.C.K., and D.J.A.W. analyzed data; S.A.B., A.S., P.C.K., and D.J.A.W. wrote the paper. 
Pelkey et al., 2017; Booker and Vida, 2018). INs possess diverse dendritic arbors, receiving glutamatergic inputs from both local and distant sources where synaptically released glutamate binds to and activates ligand-gated ion channels: chiefly AMPAreceptors (AMPARs) and NMDA receptors (NMDARs), that give rise to short $(<10 \mathrm{~ms})$ and long (100-1000 ms) synaptic events respectively (CullCandy et al., 2001). NMDARs have been proposed as the archetypal receptor underlying synaptic plasticity, and thus memory formation, in many cell types (Morris et al., 1990; Tsien et al., 1996; Morris, 2013).

NMDARs exist as tetrameric receptor complexes comprised of two GluN1 and two GluN2 subunits, the latter existing as four separate gene products (GluN2A-D; Gielen et al., 2009; Wyllie et al., 2013). During early brain development, GluN2B and GluN2D are the dominant isoforms in the hippocampus (Monyer et al., 1994; Flint et al., 1997; Martel et al., 2009; McKay et al., 2012). In mature principal hippocampal neurons GluN2A and GluN2B subunits predominate while GluN2D subunits have been reported in some IN populations (Engelhardt et al., 2015; Perszyk et al., 2016; Garst-Orozco et al., 2020). Native NMDARs can exist as either diheteromers (i.e., GluN1/ GluN2A) or as triheteromeric assemblies (i.e., GluN1/2A/ 2B) with ligand binding, receptor kinetics and ion channel conductance being conferred by the identity of the nature of the GluN2 subunits present (Stern et al., 1992; Wyllie et al., 1996; Gielen et al., 2009; Hansen et al., 2014). Indeed, the presence of GluN2A subunits confers fast kinetics, whereas the presence of GluN2B and GluN2D subunits confer increasingly slow kinetics (Monyer et al., 1994; Vicini et al., 1998; Wyllie et al., 1998; for review, see Wyllie et al., 2013). Synaptically released glutamate, together with glycine (or D-serine), binds to synaptic and extrasynaptic NMDARs, and at depolarized membrane potentials the relief of voltage-dependent $\mathrm{Mg}^{2+}$ block allows ion conduction (reviewed in Hansen et al., (2018)). This requirement of postsynaptic depolarization and presynaptic neurotransmitter release for NMDAR opening defines them as a coincidence detector, critical for the establishment of Hebbian plasticity (Seeburg et al., 1995). Given these properties, the stoichiometry of NMDARs subunits confer distinct functional synaptic properties (Stern et al., 1992; Cull-Candy et al., 2001; Wyllie et al., 2013). Several studies have aimed to identify the contribution of NMDAR subunits to the different excitatory and inhibitory neuronal populations. The current understanding is that mature CA1 PyrCs exclusively express GluN2A/B-

This research was supported by the Biotechnology and Biological Sciences Research Council (Grant BB/N015878/1; to P.C.K. and D.J.A.W.) and the Simons Foundation Autism Research Initiative (Grant 529085; to P.C.K.).

We thank the members of the Kind and Wyllie laboratories for constructive comments and input during the course of this study.

Correspondence should be addressed to Sam A. Booker at sbooker@ ed.ac.uk or David J. A. Wyllie at david.j.a.wyllie@ed.ac.uk.

https://doi.org/10.1523/ENEURO.0552-20.2021 Copyright $@ 2021$ Booker et al.

This is an open-access article distributed under the terms of the Creative Commons Attribution 4.0 International license, which permits unrestricted use, distribution and reproduction in any medium provided that the original work is properly attributed. containing NMDARs (Flint et al., 1997; Gray et al., 2011). Meanwhile, hippocampal INs possess varied AMPARand NMDAR-mediated responses dependent on cell type (Akgül and McBain, 2016), and all major IN classes appear to express RNA for GluN2A/B/D subunits (Perszyk et al., 2016). Functional NMDARs have been shown on a variety of IN subtypes, including those expressing parvalbumin (PV; Korotkova et al., 2010; Billingslea et al., 2014) and cholecystokinin (CCK; Kotzadimitriou et al., 2018), morphologically defined basket cells (BCs) and dendritic inhibitory cells (Matta et al., 2013), oriens/alveus INs (Hájos et al., 2002), and neurogliaform neurons (Chittajallu et al., 2017). Despite this, many studies have been performed in juvenile rodent models and have not been able to determine the relative role of GluN2A in IN subtypes, because of the paucity of pharmacological modulators of this receptor subunit. Moreover, GluN2A-containing NMDARs are proposed to contribute to the induction of long-term potentiation (LTP) and GluN2B-containing NMDARs contribute to both long-term depression and LTP (Liu et al., 2004; Volianskis et al., 2013), while GluN2D NMDARs may contribute to both short- and long-term plasticity (Volianskis et al., 2013; Tozzi et al., 2016). Thus, determining the functional properties of NMDARs in INs will provide insight into their synaptic recruitment and plasticity (Booker and Wyllie, 2021).

This study assesses the relative NMDAR-mediated synaptic currents and the contribution of GluN2 subunits in morphologically and immunohistochemically identified hippocampal INs from wild-type and GluN2A-null outbred rats. We achieve this by performing whole-cell patchclamp recording from INs and PyrCs to examine the NMDAR-mediated synaptic current in the presence of pharmacological manipulation and the role of GluN2 subunits in the generation of synaptic plasticity.

\section{Materials and Methods}

\section{Animals}

All procedures were performed according to UK and University of Edinburgh guidelines and under the authority of Home Office Licence (P1351480E). GluN2A-null rats were generated through CRISPR/Cas9 deletion of the gene, with GluN2A protein loss shown previously (Strehlow et al., 2019). All rats were maintained on an outbred Long-Evans Hooded background, and were housed on a $12 \mathrm{~h}$ light/dark cycle with ad libitum access to food and water. Male rats were taken for recordings at 46 weeks of age to avoid potential confounds because of onset of the estrus cycle. All recordings were performed at 4-6 weeks of age. The average age of wild-type rats was $31.1 \pm 0.5 \mathrm{~d}(N=38$ rats total), and $32.4 \pm 0.8 \mathrm{~d}$ $(N=27$ rats total) for GluN2A-null rats.

\section{Acute slice preparation}

Acute brain slices were prepared as previously described (Booker et al., 2017). Rats were anesthetized with isoflurane and decapitated, and their brains were rapidly removed and placed in ice-cold carbogenated $\left(\begin{array}{lll}95 \% & \mathrm{O}_{2} / 5 \% & \mathrm{CO}_{2}\end{array}\right)$ sucrose-modified artificial CSF 
(sucrose-ACSF; in mm): $87 \mathrm{NaCl}, 2.5 \mathrm{KCl}, 25 \mathrm{NaHCO}_{3}$, $1.25 \mathrm{NaH}_{2} \mathrm{PO}_{4}, 25$ glucose, 75 sucrose, $7 \mathrm{MgCl}_{2}, 0.5$ $\mathrm{CaCl}_{2}$. Horizontal slices $(400 \mu \mathrm{m})$ containing the hippocampus were cut on an oscillating-blade vibratome (model VT1200S, Leica). Slices were placed in a submerged holding chamber in sucrose-ACSF for $30 \mathrm{~min}$ at $35^{\circ} \mathrm{C}$, then stored at room temperature.

\section{Whole-cell patch-clamp recordings}

For electrophysiological recordings, slices were transferred to a submerged recording chamber perfused with prewarmed carbogenated ACSF (in mм: $125 \mathrm{NaCl}, 2.5$ $\mathrm{KCl}, 25 \mathrm{NaHCO}_{3}, 1.25 \mathrm{NaH}_{2} \mathrm{PO}_{4}, 25$ glucose, $1 \mathrm{MgCl}_{2}$, and $2 \mathrm{CaCl}_{2}$, at a flow rate of $4-6 \mathrm{ml} / \mathrm{min}$ at $30 \pm 1^{\circ} \mathrm{C}$ ). Slices were visualized under infrared differential inference contrast microscopy with a digital camera (Orca 2, Hamamatsu; or SciCamPro, Scientifica) mounted on an upright microscope (model BX61-WI, Olympus; or Slicescope, Scientifica) with a $40 \times$ water-immersion objective lens [1.0 numerical aperture (NA), Olympus]. Whole-cell patch-clamp recordings were performed with an amplifier (Multiclamp 700B, Molecular Devices). Recording pipettes were pulled from borosilicate glass capillaries (outer diameter, $1.7 \mathrm{~mm}$; inner diameter, 1 $\mathrm{mm}$; Harvard Apparatus) on a horizontal electrode puller (model P-97, Sutter Instruments). For recordings, pipettes were filled with a either a Cs-gluconate-based (in mm: 140 Cs-gluconate, $4 \mathrm{CsCl}$, 0.2 EGTA, 10 HEPES, 2 MgATP, $2 \mathrm{Na}_{2}$ ATP, $0.3 \mathrm{Na}_{2}$ GTP, $10 \mathrm{Na}_{2}$ phosphocreatine, 2.7 biocytin, and $5 \mathrm{QX}-314$; $\mathrm{pH} 7.4,290-310 \mathrm{mOsm}$ ) or a $\mathrm{K}$-gluconate-based (in mм: $142 \mathrm{~K}$-gluconate, $4 \mathrm{KCl}$, 0.5 EGTA, 10 HEPES, $2 \mathrm{MgCl}_{2}$, $2 \mathrm{Na}_{2}$ ATP, $0.3 \mathrm{Na}_{2} \mathrm{GTP}$, $10 \mathrm{Na}_{2}$ phosphocreatine, and 2.7 biocytin; $\mathrm{pH} 7.4$, 290$310 \mathrm{mOsm}$ ) internal solution, which gave 3-5 M $\Omega$ pipette tip resistances on filling. Cells were rejected if they required a holding current of more than $-200 \mathrm{pA}$ to maintain $-70 \mathrm{mV}$ voltage clamp, series resistance started at $>30 \mathrm{M} \Omega$, or series resistance changed by $>25 \%$ over the course of the recording. The average change in series resistance was $11.6 \%\left[\right.$ mean $_{\text {(start) }}=$ $18.7 \pm 5.8$ (range, 7.0-29.9); $\operatorname{mean}_{(\mathrm{end})}=18.4 \pm 6.5$ (range, 7.6-36.5); $p=0.45$, paired Student's $t$ test].

Whole-cell recordings of pharmacologically isolated EPSCs were performed following wash-in of Cs-gluconate solution $(\sim 2-5 \mathrm{~min})$ to provide optimal voltage clamp, in the presence of picrotoxin $(50 \mu \mathrm{M})$. EPSCs were generated by a twisted Ni:Chrome bipolar wire placed either in stratum radiatum (CA1 PyrC, PV-INs, CCK-INs) or in the alveus [somatostatin (SSt) INs], reflecting major synaptic inputs to different cell types (stimulus duration, $0.1 \mathrm{~ms}$; stimulus, $20.3 \pm 18.3 \mathrm{~V}$ ). Stimuli were delivered via constant voltage stimulator (Digitimer) sufficient to produce a monosynaptic EPSC in the range of $\sim 200 \mathrm{pA}$. The amplitude of these monosynaptic AMPA-EPSCs varied between cell types ( $p=0.0016$, one-way ANOVA) but not within a cell type [CA1 PyrCs: $p=0.84$; PV INs: $p=0.83$; $p=0.84 ; p=0.69$; Holm-Sidak tests]. For AMPAR-EPSCs, 10 traces were collected at $20 \mathrm{~s}$ intervals at $-70 \mathrm{mV}$. For NMDAR-EPSCs, either CNQX was bath applied first and AMPAR-EPSC blockade observed, or the cell was held at
$+40 \mathrm{mV}$ to identify the mixed AMPAR/NMDAR-EPSCs, and then CNQX was applied. All NMDAR-EPSCs were recorded following full wash-in of CNQX at $+40 \mathrm{mV}$ using the same stimulation intensity as for AMPAR-EPSCs. Pharmacology for the specific NMDAR subunits was as follows: GluN2Bifenprodil tartrate $(10 \mu \mathrm{M})$ or NAB-14 $(10 \mu \mathrm{M})$, and both were bath applied. As NAB-14 is highly lipophilic (Yi et al., 2019), all tubing was rinsed with $100 \%$ ethanol and liberal amounts of distilled water between recordings to ensure full removal of the drug from the surfaces of perfusion tubes. All EPSC amplitudes were recorded at the peak of the EPSC, as measured over a $2 \mathrm{~ms}$ peak average. All rise times are reported as the $20-80 \%$ of the peak EPSC amplitude. Decay time constants were calculated from a monoexponential (AMPAREPSC) or biexponential (NMDAR-EPSC) curve fit to the decaying phase of the EPSC. For biexponential fits, the weighted tau was taken as the decay time constant. For all kinetic properties, only NMDAR EPSCs with amplitude $>20 \mathrm{pA}$ were included for analysis, to exclude measurement artifacts. NMDAR/AMPAR EPSC amplitude ratios were calculated from the average EPSC recorded for the respective epoch.

For LTP recordings, cells were recorded in current clamp, using a K-gluconate-based internal solution. Putative CCK INs were selected for recording in stratum radiatum and monosynaptic EPSPs were generated via bipolar electrode stimulation of the stratum radiatum, placed $\sim 500 \mu \mathrm{m}$ distal to the recorded somata. Following breakthrough into whole-cell configuration, the membrane potential was set to $-70 \mathrm{mV}$ with the application of a bias current, and the bridge was balanced. Then EPSPs with amplitude of $\sim 5 \mathrm{mV}$ (mean, $5.94 \pm$ $2.85 \mathrm{mV}$; range, $1.64-12.35 \mathrm{mV}$ ) were recorded for $5 \mathrm{~min}$ of stable baseline $(<10 \%$ change over $5 \mathrm{~min}$, calculated from a linear fit of baseline period); if stability was not achieved within $7.5 \mathrm{~min}$ of breakthrough, the recording was abandoned. Following $5 \mathrm{~min}$ of stable recording, LTP was induced, with $2 \times 100 \mathrm{~Hz}$ of tetanus stimuli, at the same strength as the baseline EPSP. Following induction, 25 min of EPSPs were recorded to assess the potentiation of the whole-cell EPSP, which was reported as the peak amplitude measured as the peak $2 \mathrm{~ms}$ response. All recordings were filtered online at $10 \mathrm{kHz}$ with the built-in four-pole Bessel filter and digitized at $20 \mathrm{kHz}$ (Digidata1440, Molecular Devices). Traces were recorded in pCLAMP 9 (Molecular Devices) and stored on a personal computer. Analysis of electrophysiological data were performed offline using the open source software package Stimfit (Guzman et al., 2014).

Following recording, all cells were resealed by carefully withdrawing the patch-pipette in a manner akin to forming an outside-out patch. The slices were then fixed in 4\% paraformaldehyde dissolved in $0.1 \mathrm{~m}$ phosphate buffer (PB) $\mathrm{pH} 7.35$, overnight at $4^{\circ} \mathrm{C}$. Slices were then transferred to $0.1 \mathrm{~m}$ PBS until processing for immunohistochemistry.

\section{Histologic processing and imaging}

Immunolabelling of recorded neurons was performed as previously described (Booker et al., 2014), slices were washed several times in PBS, then blocked in 10\% normal goat serum (NGS), $0.3 \%$ Triton $X-100$, and $0.05 \%$ $\mathrm{NaN}_{3}$ in PBS for $1 \mathrm{~h}$ at room temperature. Slices were then incubated with primary antibodies for PV 
(monoclonal mouse; 1:5000; SWANT), pre-pro-CCK (polyclonal rabbit; 1:1000; Frontiers Laboratory), or SSt (polyclonal rabbit; 1:2000; Peninsula Laboratories). Primary antibodies were diluted in PBS containing 5\% NGS, $0.3 \%$ Triton $\mathrm{X}-100$, and $0.05 \% \mathrm{NaN}_{3}$ for $72 \mathrm{~h}$ at $4^{\circ} \mathrm{C}$. Slices were thoroughly washed with PBS, and then secondary antibodies (anti-mouse or anti-rabbit; 1:1000; Alexa Fluor 488, Thermo Fisher Scientific) were applied with streptavidin conjugated to Alexa Fluor 633 (1:1000; Thermo Fisher Scientific) applied diluted in PBS containing $3 \%$ NGS, $0.1 \%$ Triton $\mathrm{X}-100$ and $0.05 \% \mathrm{NaN}_{3}$ for $3 \mathrm{~h}$ at room temperature or $24 \mathrm{~h}$ at $4^{\circ} \mathrm{C}$. Slices were rinsed in PBS then PB, and were mounted on glass slides with VECTASHIELD HardSet Antifade Mounting Medium (catalog \#H1400, Vector Laboratories). For CA1 PyrCs, the same protocol was used, albeit with streptavidin Alexa Fluor 633 applied at 1:1000.

Confocal image stacks were collected on an invert scanning-confocal microscope (LSM 510 META Confocal with Axiovert 200, Zeiss) equipped with a $20 \times(0.45 \mathrm{NA}$; Zeiss) air-immersion or a $63 \times$ (1.4 NA; Zeiss) oil-immersion objective lens. For the identification of neurons, $z-$ stacks ( $1 \mu \mathrm{m}$ steps; $1024 \times 1024$ pixels) containing the somatodendritic axis and axon distribution were carried out. For neurochemical identification, the somata were imaged under high magnification, and immunolabeling was assessed over the somatic focal plane. All image analysis was performed with the FIJl package of ImageJ. For reconstruction, the neurons were imaged fully then stitched, segmented, and rendered offline in FIJI, using the Simple Neurite Tracer (SNT) plug-in (Longair et al., 2011).

\section{Statistical analysis}

All experiments and analysis were performed blind to genotype. Throughout this study, data are shown as the mean \pm SD, and the number of cells $(n)$ and animals $(N)$ are indicated. The required sample size was estimated based on an assumed effect size of $20 \%$ with $15 \%$ SD at $80 \%$ power, giving a required $N=7-10 /$ group. Some data showed a $>20 \%$ effect size, thus requiring fewer biological replicates $(M)$. All data are reported as animal averages, unless stated otherwise, and are shown alongside estimation statistics of difference between means and confidence intervals (Cls) in the form ( $r$ value, effect size, 95\% confidence interval, $p$ value, test performed), the usefulness of which has been demonstrated previously (Manouze et al., 2019). We performed statistical comparisons of effect size in a paired or unpaired manner, using Student's $t$ test, MannWhitney test, or Wilcoxon signed-rank test, depending on whether data were normally distributed, which was confirmed with the Anderson-Darling test. For group analysis, one-way ANOVA was performed. Statistical significance was assumed if $p<0.05$.

\section{Data availability}

The data that support the findings of this study are available from the corresponding author on reasonable request.

\section{Results}

\section{Absence of GluN2A subunits leads to slowed kinetics of NMDAR-EPSCs in CA1 PyrCs}

To first confirm that loss of GluN2A receptors leads to functional changes in NMDAR signaling, we made recordings from identified CA1 PyrCs (Fig. $1 A$ ) in both wild-type ( $n=20$ cells; $N=13$ rats) and GluN2A-null littermate rats ( $n=21$ cells; $N=11$ rats). In all recordings, large AMPARmediated EPSCs were recorded in response to electrical stimulation of putative Schaffer collateral afferents in stratum radiatum (Fig. 1B). These EPSCs had an average amplitude of $357 \pm 198 \mathrm{pA}$ in wild-type rats, which was similar to that of $509 \pm 228 \mathrm{pA}$ in GluN2A-null rats $(r=0.12,-152 ; \mathrm{Cl},-332,+29 ; p=0.095$, unpaired Student's $t$ test). The AMPAR rise time was $2.1 \pm 0.7 \mathrm{~ms}$ and had a decay time constant of $8.5 \pm 1.7 \mathrm{~ms}$ in wildtype rats, which was very similar in the GluN2A-null PyrCs (rise time: $r=0.002,+0.053 ; \mathrm{Cl},-0.46,0.57 ; p=0.83$; decay time constant: $r=0.03,+0.80 ; \mathrm{Cl},-1.23,2.82$; $p=0.42$, unpaired Student's $t$ tests). When recorded at $+40 \mathrm{mV}$ in the presence of $10 \mu \mathrm{m} \mathrm{CNQX}$, we consistently observed NMDAR-EPSCs (Fig. 1B), which in wild-type rats had a rise time of $3.6 \pm 0.7 \mathrm{~ms}$ and a weighted decay time constant of $120.5 \pm 39.4 \mathrm{~ms}$. The average NMDAREPSC had an amplitude of $129 \pm 73 \mathrm{pA}$, giving rise to an average NMDAR/AMPAR ratio of $0.43 \pm 0.22$. Consistent with GluN2A subunits conferring rapid gating kinetics to NMDARs, we observed a slowing of NMDAR-EPSCs in the GluN2A-null rat (Fig. $1 B$ ) with $20-80 \%$ rise time slowed by $27 \%(r=0.15,+0.55 ; \mathrm{Cl},-0.03,1.12 ; p=0.06$, unpaired Student's $t$ test; Fig. $1 C$ ) and the decay time constant slowed by $75 \%(r=0.13,+66.1 ; \mathrm{Cl}, 32.3,99.9$; $p=0.0005$, unpaired Student's $t$ test; Fig. 1D). We observed a $28 \%$ reduction in the NMDAR/AMPAR ratio associated with loss of the GluN2A subunit, which was not significantly different $(r=0.43,-0.13 ; \mathrm{Cl},-0.28,0.02$; $p=0.08$, unpaired Student's $t$ test; Fig. $1 E$ ), suggesting that the total number of NMDARs may be reduced at Schaffer collateral synapses. Together, these data confirm that NMDARs in CA1 PyrCs contain GluN2A subunits, which contribute to the kinetics properties of the receptor.

\section{NMDARs in hippocampal INs express variable levels of GluN2A}

We next assessed the contribution of GluN2A subunits to synaptic NMDARs in identified hippocampal INs. We first sought to identify EPSCs in PV INs, which were located in and around stratum pyramidale, with large somata with multipolar dendrites. These were initially selected based on low membrane resistance and fast membrane decay times on breakthrough into the whole-cell configuration. For this study we identified 20 PV INs from 15 wildtype rats, and 14 PV INs from 13 GluN2A-null rats, which all displayed clear immunolabelling for PV. In wild-type rats, $50 \%$ ( $n=10$ cells) of PV INs were identified as BCs with axons localized to stratum pyramidale (Fig. $2 A$ ) and $35 \%$ ( $n=7$ cells) had axons localized to stratum radiatum and stratum oriens, thus representing likely bistratified cells; the remaining three cells had axons cut close to the 

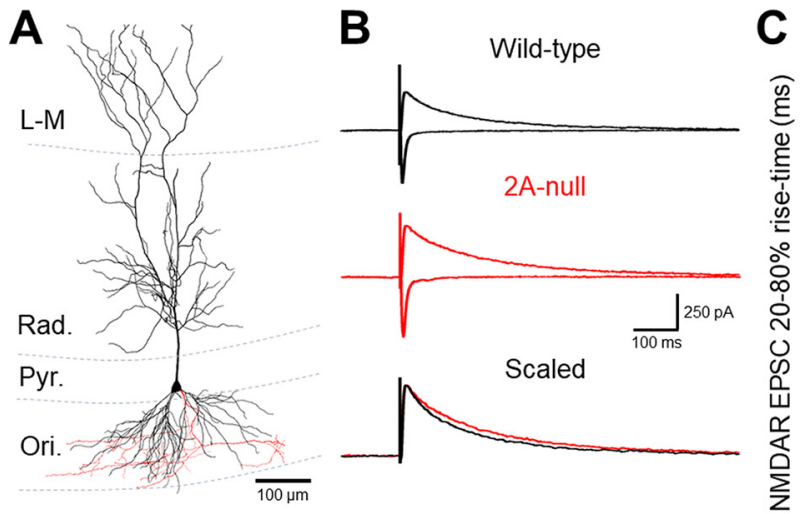

D

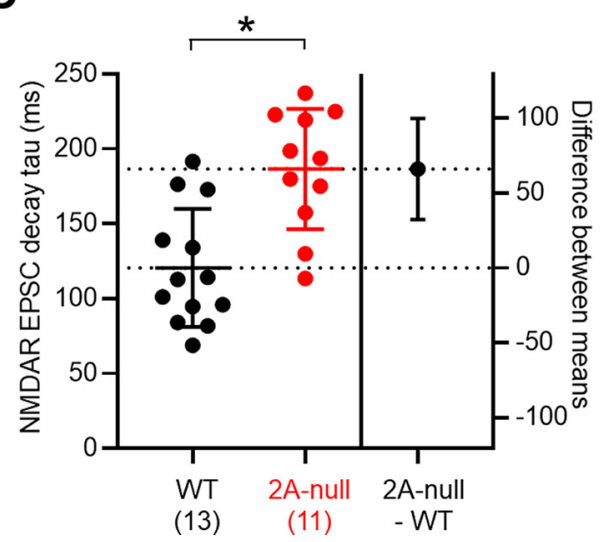

E
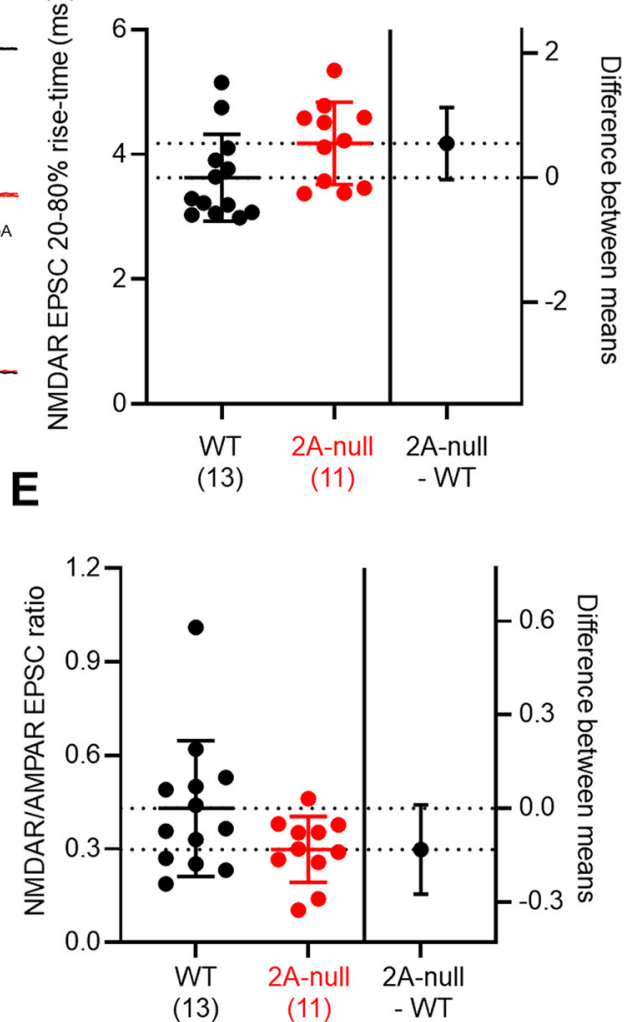

Figure 1. The absence of GluN2A confers slowed NMDAR kinetics on CA1 PyrCs. A, Reconstruction of a CA1 PyrC showing orientation with respect to the hippocampal layers stratum oriens (Ori.), pyramidale (Pyr.), radiatum (Rad.), or lacunosum-moleculare (L-M). Somatodendritic axis (black) and axonal arborization (red) are indicated. B, Representative EPSCs recorded from CA1 PyrCs from wild-type (black) and GluN2A-null (red) rats. AMPAR-EPSCs (inward currents) and NMDAR-EPSCs (outward currents) are shown. The peak scaled NMDAR traces are shown below to indicate the slowing of the NMDAR-EPSC. $\boldsymbol{C}$, NMDAR-EPSC rise times, quantified for all recorded CA1 PyrCs. Data from individual cells are shown as filled circles from wild-type rats (black; $n=20$ cells; $N=13$ rats) and GluN2A-null rats (2A-null, red; $n=21$ cells; $N=11$ rats). $\boldsymbol{D}$, NMDAR-EPSC decay time constants (tau) from the weighted tau of a biexponential curve fit. $E$, NMDAR/AMPAR ratio of EPSCs elicited by Schaffer collateral stimulation. Fewer rats are shown for kinetic values because of the 20 pA cutoff imposed on kinetic data. Data are shown as the mean \pm SD, alongside the difference between the means $\pm \mathrm{Cl}$. ${ }^{*} p<0.05$, Student's $t$ test.

soma, thus preventing further identification. In GluN2Anull rats, $79 \%$ of recovered PV INs were BCs ( $n=11$ cells), $14 \%$ were bistratified ( $n=2$ cells), and one cell could not be identified because of a proximally cut axon.

In PV INs, the stimulation of stratum radiatum in the presence of picrotoxin $(50 \mu \mathrm{m})$ at $-70 \mathrm{mV}$ gave rise to AMPARmediated EPSCs with amplitudes of $373 \pm 306 \mathrm{pA}$ in wildtype rats and $350 \pm 166 \mathrm{pA}$ in GluN2A-null rats $(r=0.003$, 24.1; $\mathrm{Cl},-173,221 ; p=0.80$, unpaired Student's $t$ test), with similar rise times $\mathrm{WT}, 1.6 \pm 1.6 \mathrm{~ms}$; GluN2A-null, $1.6 \pm$ $1.3 \mathrm{~ms} ; r=0.0007,-0.08 ; \mathrm{Cl},-0.08,0.56 ; p=0.80$, unpaired Student's $t$ test), but 33\% longer decay time constants (WT, $6.7 \pm 2.1 \mathrm{~ms}$; GluN2A-null, $9.0 \pm 3.4 \mathrm{~ms} ; r=0.15,2.3 ; \mathrm{Cl}$, $0.06,4.5 ; p=0.05$, unpaired Student's $t$ test). NMDAR-mediated EPSCs, recorded at $+40 \mathrm{mV}$ in PV INs from WT rats (Fig. 2B) had an amplitude of $76 \pm 62$ pA, a $20-80 \%$ rise time of $3.2 \pm 0.7 \mathrm{~ms}$ (Fig. $2 \mathrm{C}$ ), and a decay time constant of $90.1 \pm 28.4 \mathrm{~ms}$ (Fig. 2D), which was $\sim 30 \mathrm{~ms}$ faster than those of CA1 PyrCs $(r=0.17,30.4 ; \mathrm{Cl},-60.0,-0.76 ; p=$ 0.045 , unpaired Student's $t$ test). Because of the thresholding of NMDAR-EPSCs at $20 \mathrm{pA}$ for kinetic measurements, three animals were excluded from these analyses. The NMDAR/ AMPAR ratio for wild-type PV INs was $0.26 \pm 0.17$, which was lower than that of CA1 PyrCs $(r=0.16,-0.17 ; \mathrm{Cl},-0.32$, $-0.01 ; p=0.038$, unpaired Student's $t$ test). In terms of cell type-specific effects, the decay time constants of PV BCs $(109.2 \pm 21.1 \mathrm{~ms})$ tended to be longer than those of PV bistratified cells $(78.0 \pm 36.1 \mathrm{~ms} ; r=0.25,-31.3 ; \mathrm{Cl},-69.3,6.8$; $p=0.097$, unpaired Student's $t$ test), despite similar NMDAR/ AMPAR ratios $(r=0.007,0.035 ; \mathrm{Cl},-0.21,0.28 ; p=0.77$, unpaired Student's $t$ test). All kinetic data for identified subtypes are shown in Table 1.

Compared with wild-type rats, NMDAR-EPSCs recorded in PV INs from GluN2A-null rats had similar amplitudes of $51 \pm 46 \mathrm{pA}(r=0.54,-25.1 ; \mathrm{Cl},-68.5,18.3$; $p=0.25$, unpaired Student's $t$ test) and rise times of $3.1 \pm 1.2 \mathrm{~ms}(r=0.001,-0.06 ; \mathrm{Cl},-0.91,0.79 ; p=0.89$, unpaired Student's $t$ test). Consistent with the contribution of GluN2A subunits to NMDAR-EPSCs evoked in PV INs, we measured a $75 \%$ increase in the decay time 
A

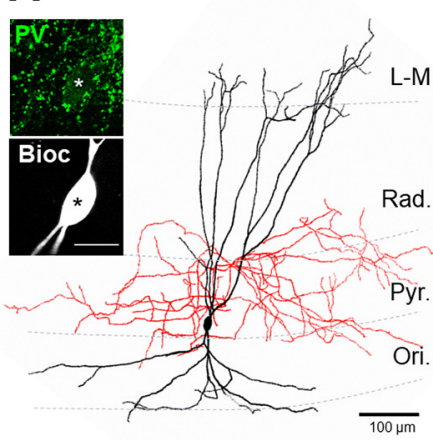

D

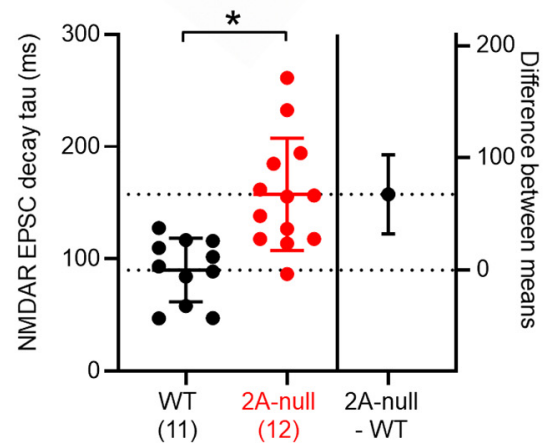

B

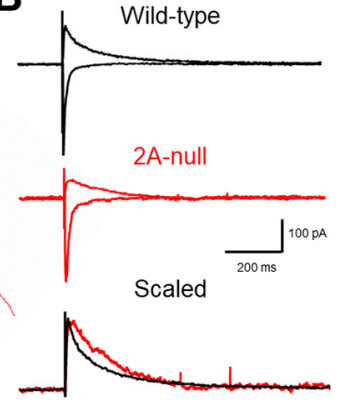

E

E

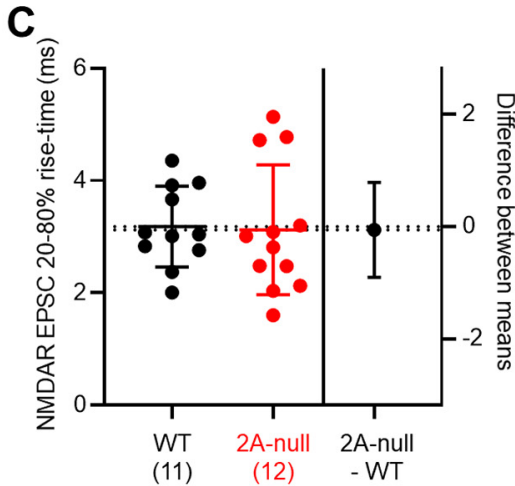

(11) $\quad(12) \quad-$ WT

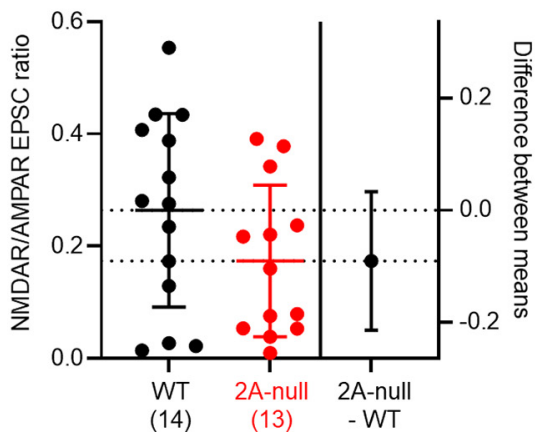

Figure 2. GluN2A subunits contribute to NMDAR-EPSCs in identified PV INs. $\boldsymbol{A}$, Reconstruction of a PV IN recorded in CA1 with respect to the hippocampal layers, with the somatodendritic axis indicated in black and axons localized to stratum pyramidale in red. Inset, Immunohistological labeling for PV (green) aligned (asterisk) to the biocytin-filled somata (black and white). Scale bar, $10 \mu \mathrm{m}$. $\boldsymbol{B}$, Representative monosynaptic AMPAR- and NMDAR-mediated EPSCs recorded from PV INs in wild-type (black) and 2A-null (red) rats. The scaled NMDAR-mediated EPSC (bottom) indicates the slowing of response in the GluN2A-null rat line. $\boldsymbol{C}$, NMDAR-EPSC rise times, quantified for identified PV-INs from wild-type (black; $N=14$ rats) and 2A-null (red; $N=13$ rats) rats, with individual cells shown overlain (filled circles); fewer rats are shown for kinetic values because of the 20 pA cutoff. $\boldsymbol{D}$, Quantification of NMDARmediated EPSC decay time constants (tau). $\boldsymbol{E}$, NMDAR/AMPAR ratio of EPSCs elicited by Schaffer collateral stimulation. Data are shown as the mean $\pm \mathrm{SD}$. ${ }^{*} p<0.05$, Student's $t$ test.

constant to $158 \pm 50 \mathrm{~ms}$ in GluN2A-null rats compared with wild-type rats $(r=0.42,67.5 ; \mathrm{Cl}, 32.2,102.8$; $p=0.0007$, unpaired Student's $t$ test; Fig. 2D). PV INs in GluN2A-null rats had a NMDAR/AMPAR ratio of $0.17 \pm$
0.14 , which was lower but not significantly different from that of WT rats $(r=0.084,-0.09 ; \mathrm{Cl},-0.21,0.03 ; p=0.14$, unpaired Student's $t$ test; Fig. $2 E$ ). Although not statistically different between genotypes, the decay kinetics for

Table 1: Key properties of NMDAR-mediated EPSCs in PyrCs and in morphotypes in CA1 of the hippocampus

\begin{tabular}{|c|c|c|c|c|c|c|c|c|}
\hline \multirow[b]{2}{*}{ Cell type } & \multicolumn{2}{|c|}{$N$} & \multicolumn{3}{|c|}{ Decay time constant (ms) } & \multicolumn{3}{|c|}{ NMDAR/AMPAR ratio } \\
\hline & WT & 2A null & WT & 2A null & $p$ & WT & 2A null & $p$ \\
\hline \multicolumn{9}{|l|}{ PyrC } \\
\hline All & 13 & 7 & $120 \pm 39$ & $187 \pm 40$ & 0.0007 & $0.43 \pm 0.22$ & $0.30 \pm 0.11$ & 0.08 \\
\hline \multicolumn{9}{|l|}{ PV } \\
\hline All & 14 & 13 & $90 \pm 28$ & $158 \pm 50$ & 0.0007 & $0.26 \pm 0.17$ & $0.17 \pm 0.14$ & 0.14 \\
\hline $\mathrm{BC}$ & 9 & 11 & $109 \pm 21$ & $156 \pm 54$ & 0.0013 & $0.27 \pm 0.25$ & $0.18 \pm 0.20$ & 0.40 \\
\hline Bistratified & 6 & 2 & $78 \pm 36$ & $154 \pm 51$ & $\mathrm{n} / \mathrm{a}$ & $0.30 \pm 0.14$ & $0.24 \pm 0.22$ & $\mathrm{n} / \mathrm{a}$ \\
\hline \multicolumn{9}{|l|}{ SSt } \\
\hline All & 14 & 12 & $85 \pm 28$ & $159 \pm 60$ & 0.0042 & $0.46 \pm 0.48$ & $0.53 \pm 0.51$ & 0.90 \\
\hline OLM & 9 & 8 & $76 \pm 25$ & $145 \pm 27$ & 0.0005 & $0.37 \pm 0.38$ & $0.43 \pm 0.51$ & 0.35 \\
\hline \multicolumn{9}{|l|}{ CCK } \\
\hline All & 27 & 16 & $170 \pm 64$ & $152 \pm 44$ & 0.34 & $0.63 \pm 0.36$ & $0.55 \pm 0.36$ & 0.53 \\
\hline $\mathrm{BC}$ & 14 & 7 & $187 \pm 51$ & $133 \pm 35$ & 0.0216 & $0.50 \pm 0.37$ & $0.57 \pm 0.44$ & 0.69 \\
\hline SCA/ADA & 15 & 5 & $193 \pm 100$ & $177 \pm 38$ & 0.86 & $0.61 \pm 0.29$ & $0.69 \pm 0.18$ & 0.46 \\
\hline PPA & 5 & 2 & $160 \pm 59$ & $145 \pm 10$ & $\mathrm{n} / \mathrm{a}$ & $0.81 \pm 0.59$ & $0.67 \pm 0.17$ & $\mathrm{n} / \mathrm{a}$ \\
\hline
\end{tabular}

Summary of NMDAR-mediated EPSC decay time constant and NMDAR/AMPAR ratio from identified morphotypes of hippocampal INs. Statistics are shown as $p$ values reported from unpaired Student's two-tailed $t$ tests; where statistical significance was observed this has been indicated (bold). Data are shown as the mean $\pm \mathrm{SD}$ 

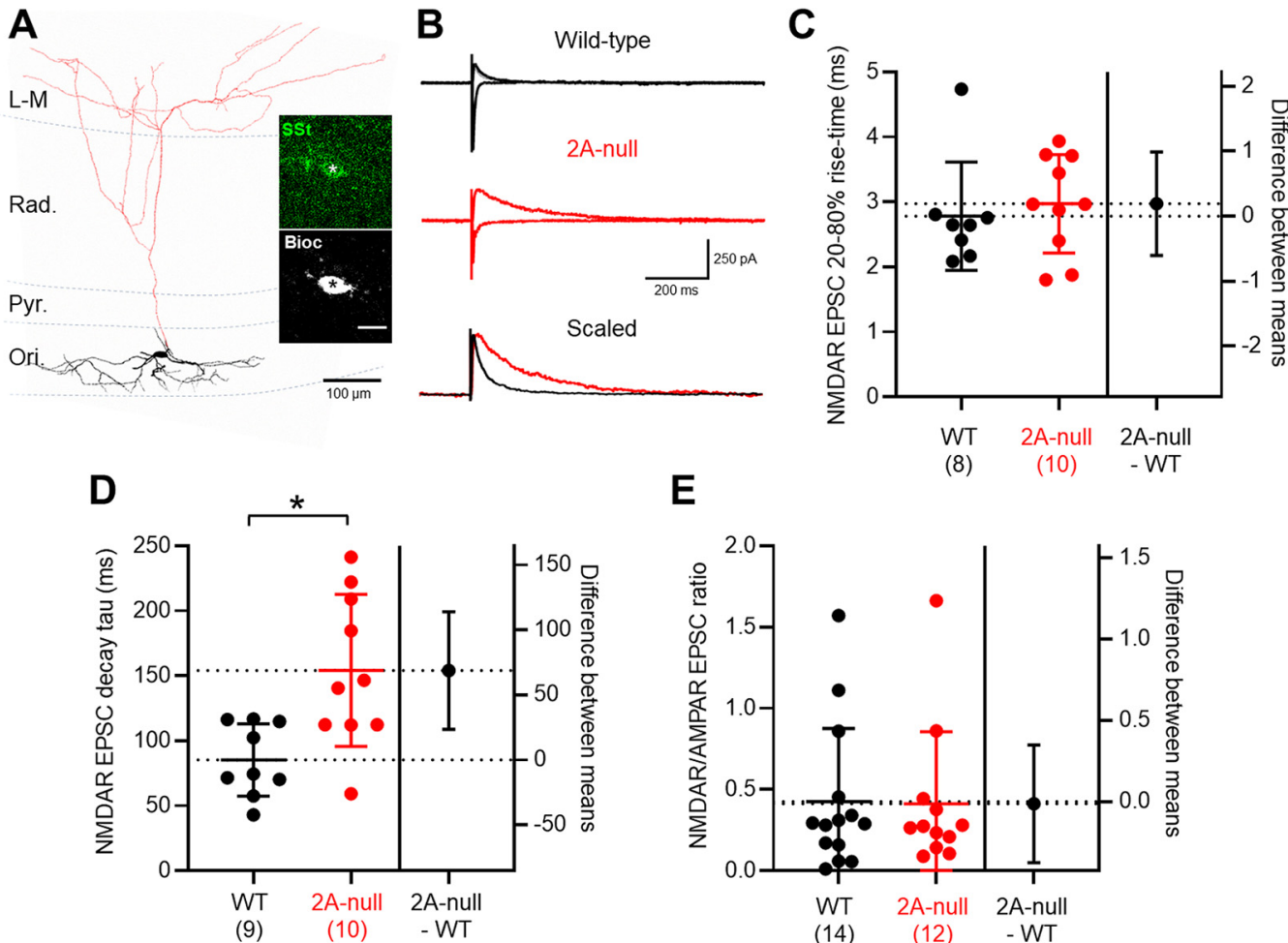

E

(8) (10) - WT

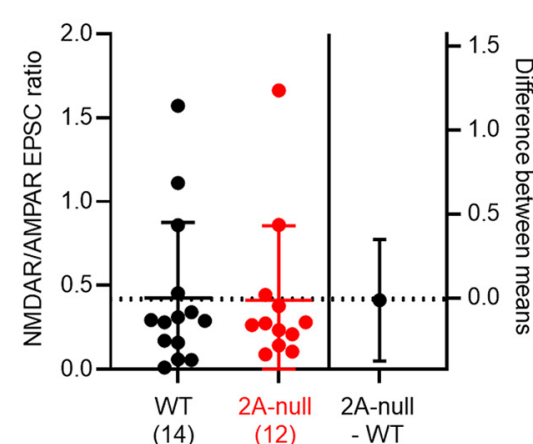

Figure 3. GluN2A is a major NMDAR subunit in SSt INs. A, Reconstructed CA1 SSt IN shown with respect to the hippocampal layers, with somatodendritic axis confined to stratum oriens (black) and axons localized to stratum lacunosum-moleculare (L-M) in red. Inset, Immunolabelling for SSt (green) of the biocytin (Bioc)-filled somata (black and white). Scale bar, $10 \mu \mathrm{m}$. B, Representative monosynaptic AMPAR- and NMDAR-mediated EPSCs recorded from SSt INs in wild-type (black) and 2A-null (red) rats. The scaled NMDAR-mediated EPSC (bottom) indicates the slower response in the GluN2A-null rats. $\boldsymbol{C}$, NMDAR-EPSC rise times, quantification in SSt INs, with individual cells from wild-type (black, $N=14$ rats) and 2A-null (red, $N=12$ rats) rats shown overlain (filled circles); fewer rats are shown for kinetic values because of the $20 \mathrm{pA}$ cutoff. $\boldsymbol{D}$, Quantification of NMDAR-mediated EPSC decay time constants (tau). E, NMDAR/AMPAR ratio of EPSCs elicited by alveus stimulation. Data are shown as the mean \pm SD. ${ }^{*} p<0.05$, Student's $t$ test.

identified BCs and bistratified cells generally obeyed the population average (Table 1). Consistent with their decay time constants in wild-type rats, BCs showed an $\sim 50 \%$ slowing of the NMDAR-EPSC decay in GluN2Anull rats, while bistratified cells showed $200 \%$ slowing in decay time constants (Table 1). These data suggest that GluN2A-containing NMDARs contribute to synaptic currents in PV-INs, comparable to that of CA1 PyrCs, with noted differences between the morphologic subtypes identified.

We next asked whether the canonical feedback INs expressing SSt (Fig. 3A; Booker et al., 2018), possessed NMDAR-EPSCs mediated by GluN2A; all cells were included in our clear immunolabeling for SSt at the level of the soma (Fig. $3 A$, inset). The major synaptic inputs to SSt INs arise from local CA1 PyrCs (Blasco-lbáñez and Freund, 1995), as such we used an alveus extracellular stimulation to elicit monosynaptic AMPAR-EPSCs and NMDAR-EPSCs (Fig. 3B), as stratum radiatum stimulation would lead to disynaptic responses. AMPAR-EPSCs in SSt INs had comparable amplitudes of $256 \pm 178 \mathrm{pA}$ in wild-type rats ( $n=17$ cells, $N=14$ rats) and $194 \pm 117 \mathrm{pA}$ in GluN2A-null rats $(n=17$ cells, $N=12$ rats; $r=0.043$, $62.4 ; \mathrm{Cl},-62.2,187.0 ; p=0.31$, unpaired Student's $t$ test). Neither the $20-80 \%$ rise time $(r=0.074,0.51 ; \mathrm{Cl}$, $-0.27,1.28 ; p=0.38$, Mann-Whitney test) nor decay the time constant $(r=0.09,3.43 ; \mathrm{Cl},-1.17,8.02 ; p=0.14$, unpaired Student's $t$ test) of AMPAR-EPSCs were different between genotypes.

In wild-type rats, NMDAR-EPSCs had an average amplitude of $80 \pm 69 \mathrm{pA}$. NMDAR-EPSCs had a $20-80 \%$ rise time of $2.8 \pm 0.8 \mathrm{~ms}$ (Fig. $3 C$ ), decay time constants of $85 \pm 28 \mathrm{~ms}$ (Fig. 3D), and a NMDAR/AMPAR ratio of $0.43 \pm 0.45$ (Fig. 3E). In seven SSt INs, it was not possible to measure NMDAR-EPSC kinetics because of their failure to reach the threshold $20 \mathrm{pA}$ amplitude for such measurements. The measured decay time constants of SSt INs were $30 \%$ faster than for CA1 PyrCs $(r=0.21,-35.3$; Cl, $-67.2,-3.4 ; p=0.032$, unpaired Student's $t$ test). In GluN2A-null rats, we observed NMDAR-EPSCs of similar amplitude (68 $\pm 54 \mathrm{pA} ; r=0.009,-0.01 ; \mathrm{Cl},-0.38,0.35$; $p=0.94$, unpaired Student's $t$ test), which resulted in a comparable NMDAR/AMPAR ratio of $0.41 \pm 0.44(r=$ $0.0002,-35.3 ; \mathrm{Cl},-67.2,-3.4 ; p=0.90$, Mann-Whitney test; Fig. $3 E$ ). These NMDAR-EPSCs had similar rise times of $3.0 \pm 0.8(r=0.015,0.19 ; \mathrm{Cl},-0.65,1.04 ; p=$ 0.63 , unpaired Student's $t$ test; Fig. $3 C$ ), but had decay time constants of $159 \pm 60 \mathrm{~ms}$, which was $86 \%$ longer 


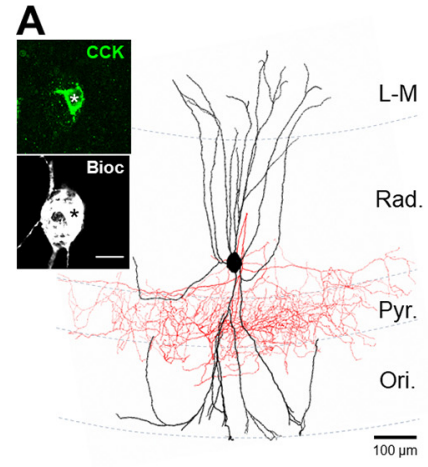

D
B

B Wild-type

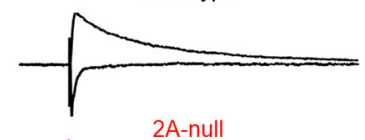

C

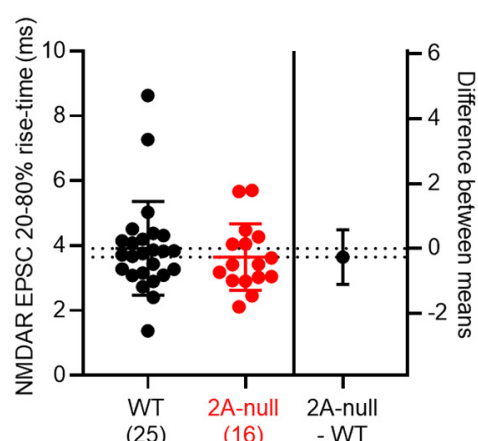

E
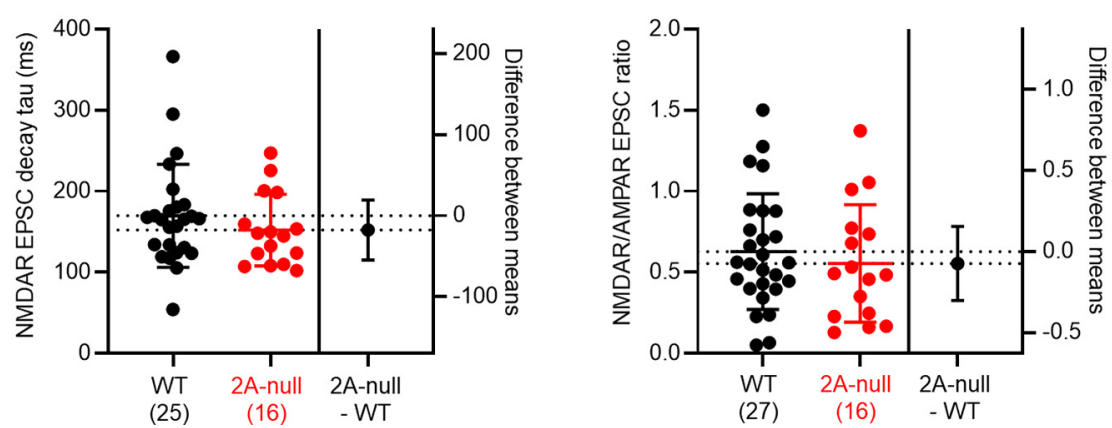

Figure 4. GluN2A does not significantly contribute to synaptic NMDAR-mediated EPSCs in CCK INs. A, Reconstructed CCK BC with respect to the hippocampal layers, with the somatodendritic axis covering all layers (black) and axons localized to stratum pyramidale (red). Inset, Immunolabelling for pre-pro-CCK (green) of the IN somata (black and white). Scale bar, $10 \mu \mathrm{m}$. B, Monosynaptic AMPAR- and NMDAR-mediated EPSCs recorded from CCK INs in wild-type (black) and 2A-null (red) rats. The scaled NMDARmediated EPSC (bottom) indicates no change in decay times in GluN2A-null rats. $\boldsymbol{C}$, NMDAR-EPSC rise times in CCK INs, with individual cells from wild-type (black, $N=26$ rats) and 2A-null (red; $N=16$ rats) shown overlain (filled circles); fewer rats are shown for kinetic values because of the $20 \mathrm{pA}$ cutoff. $\boldsymbol{D}$, Quantification of NMDAR-mediated EPSC decay time constants. $\boldsymbol{E}$, NMDAR/AMPAR ratio of EPSCs elicited by stratum radiatum stimulation. Data are shown as the mean $\pm \mathrm{SD}$.

than those of wild-type $(r=0.41,73.5 ; \mathrm{Cl}, 26.7,120.2$; $p=0.004$, unpaired Student's $t$ test; Fig. 3D). These properties were consistent when tested within the only morphotype identified in this study, the so-called stratum oriens/ lacunosum-moleculare (OLM) cell, which had decay kinetics overlapping with the population average of all SSt INs (Table 1). Together, these data suggest that NMDAREPSCs are mediated by GluN2A subunits to a large extent in SSt INs.

A major subtype of hippocampal INs is composed of those INs expressing the neuropeptide CCK (Booker and Vida, 2018), which likely reflect caudal ganglionic eminence INs previously identified as containing high levels of NMDARs (Matta et al., 2013) and were proposed to express GluN2A mRNA (Perszyk et al., 2016). To determine the contribution of GluN2A to synaptic currents in these neurons, we performed recordings of AMPAR-EPSCs and NMDAR-EPSCs from identified CCK INs in wild-type rats $(n=56$ cells, $N=27$ rats) and GluN2A-null rats $(n=23$ cells, $N=16$ rats), which were all confirmed with pre-proCCK immunolabeling (Booker et al., 2017). The cells recovered comprised BCs ( $n=15$; Fig. 4A), Schaffer collateral-associated/apical dendrite-associated cells (SCA/ ADA, $n=21$ ), and perforant path-associated (PPA; $n=6$ cells) cells in wild-type rats; the remaining cells $(n=14)$ had their axon cut close to the cell body, preventing further classification. In GluN2A-null rats, we positively identified BCs $(n=7)$, SCA/ADA cells $(n=7)$, and PPA cells $(n=2)$; the remaining cells had a cut axon $(n=7)$ and, thus, could not be classified.

AMPAR-EPSCs recorded from CCK INs in wild-type rats had an average amplitude of $204 \pm 90 \mathrm{pA}$, which was similar to that recorded in GluN2A-null rats $(262 \pm 129$; $r=0.06,-57.1 ; \mathrm{Cl},-124.8,10.56 ; p=0.10$, unpaired Student's $t$ test). There were no observed differences in AMPAR-EPSC $20-80 \%$ rise time $\left(r=2 \times 10^{-5}, 0.02\right.$; Cl, $-1.68,1.73 ; p=0.66$, Mann-Whitney test) or decay time constant $\left(r=4 \times 10^{-4},-0.29 ; \mathrm{Cl},-4.59,4.02 ; p=0.86\right.$, Mann-Whitney test). NMDAR-EPSCs were elicited, as for PyrCs and PV INs, by stimulation of stratum radiatum in the presence of picrotoxin at $+40 \mathrm{mV}$ (Fig. $4 B$ ). In wildtype rats, the average NMDAR-EPSCs had an amplitude of $99 \pm 48 \mathrm{pA}$, with a rise time of $3.9 \pm 1.4 \mathrm{~ms}$ (Fig. $4 C$ ), a decay time constant of $170 \pm 64 \mathrm{~ms}$ (Fig. 4D), and a NMDAR/AMPAR ratio of $0.63 \pm 0.36$ (Fig. $4 E$ ). There was no apparent difference in NMDAR-EPSC properties observed between morphotypes of CCK INs (Table 1). Comparison of NMDAR-EPSCs in the GluN2A-null rats (Fig. 4B) did not indicate a change in rise time (3.7 \pm $1.0 \mathrm{~ms} ; r=0.01,-0.27 ; \mathrm{Cl},-1.11,0.57 ; p=0.46$, Mann- 
A

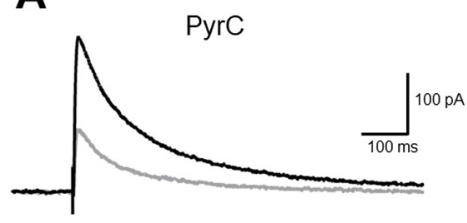

PV IN

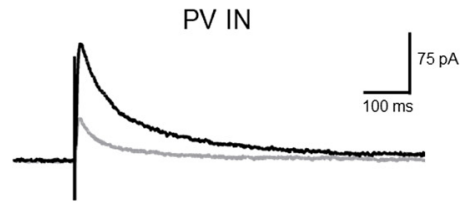

C

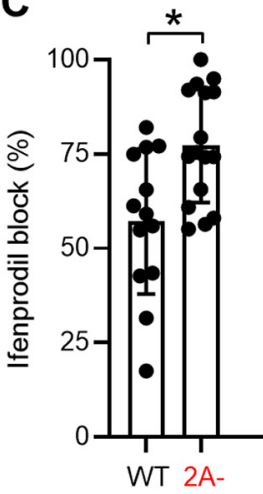

(13) null
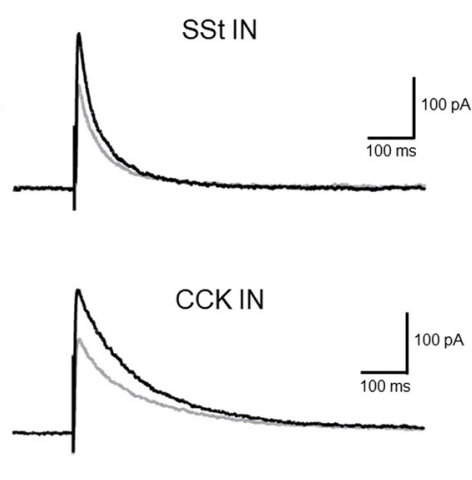

B

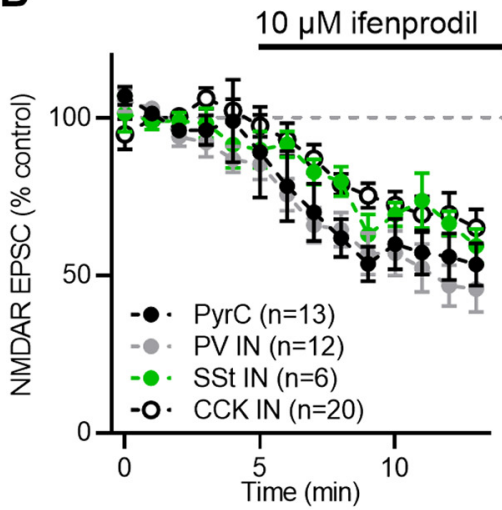

D

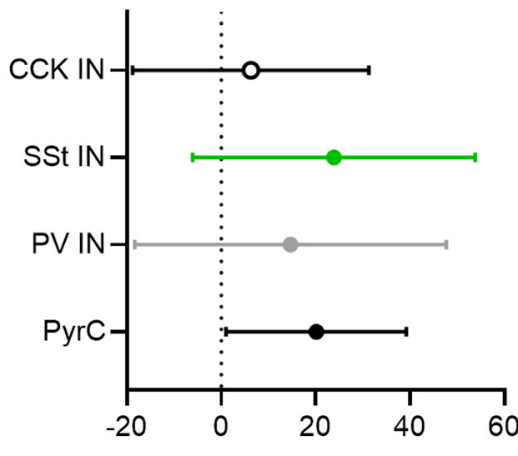

Difference between means

Figure 5. GluN2B-containing NMDARs differentially contribute to EPSCs in identified hippocampal neurons. A, Representative NMDAR-mediated EPSCs recorded at $+40 \mathrm{mV}$ in the presence of CNQX at (black traces) or following 10 min wash-in of $10 \mu \mathrm{m}$ ifenprodil (gray traces) from wild-type rats (WT) for the different cell types identified. $\boldsymbol{B}$, Time course of ifenprodil wash-in (black bar) for CA1 PyrCs (open circles), PV INs (filled black circles), SSt INs (gray circles), and a subset of CCK INs (green circles), measured as a percentage of control EPSCs per minute, compared with $100 \%$ at baseline (dashed black line). C, Quantification of ifenprodil block over the last $2 \mathrm{~min}$ for the different cell classes identified in wild-type and GluN2A-null neurons (2A-null); number of cells tested is shown in parenthesis. $\boldsymbol{D}$, Estimation plot showing the difference in ifenprodil block between wild-type and GluN2A-null cells, plotted as the difference between means $\pm 95 \%$ confidence interval. Data are shown as the mean $\pm \mathrm{SD}$. ${ }^{*} p<0.05$, paired $t$ tests.

Whitney test; Fig. $4 C$ ), an increase in decay time constant $(152 \pm 44 \mathrm{~ms} ; r=0.02,-17.5 ; \mathrm{Cl},-54.4,19.3 ; p=0.27$, Mann-Whitney test; Fig. 4D), or NMDAR/AMPAR ratio $(0.55 \pm 0.36 ; r=0.01,-0.07 ; \mathrm{Cl},-0.30,0.16 ; p=0.52$, unpaired Student's $t$ test; Fig. 4E). Compared with CA1 PyrCs, the NMDAR-EPSC decay time constant was $41 \%$ longer in CCK INs $(r=0.15,-49.2 ; \mathrm{Cl},-88.5,-9.8$; $p=0.012$, Mann-Whitney test), and the NMDAR/AMPAR ratio tended to be larger, albeit not significantly so $(r=0.08,-0.20 ; \mathrm{Cl},-0.42,0.02 ; p=0.052$, Mann-Whitney test). Together, these data suggest that CCK INs possess a high level of NMDARs with markedly different kinetics from CA1 PyrCs and appear to lack GluN2A subunits.

\section{Differential ifenprodil sensitivity of NMDARs indicates divergent GluN2B expression}

The data presented so far indicate that in CA1 PyrCs, PV INs and SSt INs GluN2A subunits contribute to synaptic NMDAR-EPSCs, but that effects of GluN2A loss are largely absent at functional synaptic receptors on CCK INs. We next sought to determine the relative expression of GluN2B subunits, through their pharmacological blockade with the selective GluN2B antagonist ifenprodil (10 $\mu \mathrm{M}$; Williams, 2001; Lei and McBain, 2002). In all cell types tested, we observed a degree of ifenprodil sensitivity when applied to pharmacologically isolated NMDAREPSCs (Fig. 5A). Blockade of NMDAR-EPSCs mediated by ifenprodil was use-dependent, as previously described (Kew et al., 1998), and developed slowly in all cells tested (Fig. 5B). In CA1 PyrCs, following a 10 min wash-in, ifenprodil produced a strong $55 \pm 21 \%$ block of native NMDAR-EPSCs, reducing the average amplitude from $136 \pm 78$ to $54 \pm 30 \mathrm{pA}(N=13$ rats; $r=0.60,-82.4 ; \mathrm{Cl}$, $-137.4,-27.4 ; p=0.009$, paired Student's $t$ test; Fig. $5 C$ ), consistent with the presence of GluN2B receptor subunits (Gray et al., 2011; Yi et al., 2019), but a greater block than for triheteromeric receptors alone (Hansen et al., 2014). This ifenprodil block in CA1 PyrCs was stronger in GluN2A-null rats at $83 \pm 13 \%(N=8$ rats; $r=0.48,-25.2$; $\mathrm{Cl},-48.7,-1.7 ; p=0.039$, paired Student's $t$ test), which is consistent with a loss of GluN2A subunit containing triheteromeric receptors (Hansen et al., 2014). In PV INs, the average NMDA-EPSC amplitude was blocked by 
$55 \pm 24 \%$, from $88 \pm 65$ to $39 \pm 33 \mathrm{pA}(N=12$ rats; $r=$ $0.61,-49.5 ; \mathrm{Cl},-79.4,-19.6 ; p=0.005$, paired Student's $t$ test; Fig. $5 C$ ). PV INs in GluN2A-null rats ( $N=3$ rats) displayed a $70 \pm 12 \%$ ifenprodil block, which was statistically not different from that in wild-type rats $(r=0.09,15.0$; $\mathrm{Cl},-17.7,47.6 ; p=0.34$, unpaired Student's $t$ test). In contrast, SSt INs displayed a $34 \pm 13 \%$ block, with NMDAR-EPSCs reduced from $145 \pm 46$ to $107 \pm 42 \mathrm{pA}$ $(N=5$ rats; $r=0.55,-37.3 ; \mathrm{Cl},-83.7,9.1 ; p=0.094$, paired Student's $t$ test), which increased to a $57 \pm 14 \%$ block in the GluN2A-null rats $(N=6, r=0.47,23.1$; Cl, 5.9, 40.3; $p=0.014$, unpaired Student's $t$ test). CCK INs displayed a $42 \pm 23 \%$ block from $126 \pm 60$ to $64 \pm 38 \mathrm{pA}$ $(N=12$ rats; $r=0.52,-30.6 ; \mathrm{Cl},-47.4,-13.8 ; p=0.002$, paired Student's $t$ test). In GluN2A-null rats $(N=3)$, ifenprodil produced a block of $57 \pm 10 \%$, which was not different from that of wild-type rats $(r=0.07,15.2 ; \mathrm{Cl},-13.4$, 43.8; $p=0.28$, unpaired Student's $t$ test). Comparison of the ifenprodil block between cell types revealed that there was no substantial difference between cell types in wildtype rats $(F=1.864, p=0.15$, one-way ANOVA; Fig. $5 C)$. In all but CCK INs, the degree of ifenprodil block tended to be greater in the GluN2A-null rat, indicating a greater contribution of this subunit to synaptic NMDARs (Fig. 5D). These data suggest that GluN2B sensitivity is broadly equivalent among PyrCs, PV, SSt, and CCK INs, and that GluN2B subunits contribute to heterotrimeric NMDARs in all cell classes.

\section{NMDARs in CCK INs are GluN2D containing and contribute to LTP induction}

From the data we have shown so far, CCK IN NMDAREPSCs appear to be unaffected by the loss of GluN2A. Furthermore, CCK INs express high levels of GluN2D mRNA 7 (Perszyk et al., 2016), and stratum radiatum INs also possess NMDAR-EPSCs sensitive to GluN2C/D modulation (Perszyk et al., 2016; Swanger et al., 2018; Yi et al., 2019). To determine whether GluN2D-containing receptors specifically contribute to NMDAR-EPSCs in CCK INs, we used the GluN2C/D-negative allosteric modulator NAB-14 (Swanger et al., 2018). As GluN2C is minimally expressed in hippocampal neurons (Wenzel et al., 1997; Perszyk et al., 2016), it is likely that the effects of NAB-14 can be attributed to NMDAR-containing GluN2D subunits. Bath application of NAB-14 (10 $\mu \mathrm{M})$ to recordings of pharmacologically isolated NMDAR-EPSCs substantially reduced their amplitude in CCK INs from wild-type and GluN2A-null rats (Fig. 6A). Following a $10 \mathrm{~min}$ wash-in of NAB-14, NMDAR-EPSCs were reduced by $65 \%(n=13$ cells; $r=0.53,-75.2 ; \mathrm{Cl},-119.9,30.5 ; p=0.0002$, Wilcoxon test), and by $37 \%$ in GluN2A-null rats $(n=5$ cells; $r=0.81,-20.4 ; \mathrm{Cl},-33.9,-6.8 ; p=0.014$, paired Student's $t$ test), which was not statistically different between genotypes $(r=0.19,-23.7 ; \mathrm{Cl},-50.0,2.6$; $p=0.074$, unpaired Student's $t$ test). Bath application of NAB-14 did not alter the $20-80 \%$ rise time of NMDAREPSCs in either wild-type $(r=0.007,0.30 ; \mathrm{Cl},-2.1,2.7$; $p=0.79$, paired Student's $t$ test) or GluN2A-null CCK INs $(r=0.097,-0.18 ; \mathrm{Cl},-0.92,0.57 ; p=0.55$, paired Student's $t$ test). As expected from a selective block of GluN2D- containing receptors, the decay time constants of NMDAREPSCs were shortened by $42 \%$ for wild-type $(r=0.61$, -109.7; Cl, $-168.3,-51.0 ; p=0.002$, paired Student's $t$ test), and by $50 \%$ for CCK INs in GluN2A-null rats ( $r=0.67$, $-98.5 ; \mathrm{Cl},-194.3,-2.7 ; p=0.046$, paired Student's $t$ test); the magnitude of this effect was not different between genotypes $(r=0.006,-3.8 ; \mathrm{Cl},-30.3,22.7 ; p=0.046$, paired Student's $t$ test). Together, these data reveal that NMDAREPSCs in CCK INs result from activation of NMDARs composed of GluN2D and GluN2B, but not GluN2A subunits.

NMDARs are known to mediate Hebbian LTP, in both PyrCs (Malenka, 1991) and INs (Lamsa et al., 2005, 2007). Indeed, GluN2A/B-containing receptors have been shown to induce LTP (Berberich et al., 2005), with the GluN2A subunit presumed to be requisite for LTP induction (Liu et al., 2004). Given the absence of GluN2A from CCK INs, we asked whether the presence of GluN2D-containing NMDARs was sufficient to induce the Hebbian form of LTP present in these INs (Lamsa et al., 2007). In wholecell recordings from CCK INs, performed in current clamp, monosynaptic EPSPs were evoked from putative Schaffer collateral afferents in stratum radiatum in the presence of picrotoxin. The average amplitude of these EPSPs was $5.4 \pm 1.9 \mathrm{mV}$ in wild-type CCK INs ( $N=9$ rats). Following $5 \mathrm{~min}$ of baseline recording, LTP was induced by delivering $2 \times 100 \mathrm{~Hz}$ trains of stimuli (duration, $1 \mathrm{~s}$ ) to the stimulated pathway, the EPSP amplitude was then measured $25 \mathrm{~min}$ after induction (Fig. 6C). In control recordings from wild-type CCK INs, this protocol resulted in potentiation of the EPSP to $59 \pm 30 \%$ increase from control EPSP at 25 min $(r=0.76,3.4 ; \mathrm{Cl}, 1.9,5.0 ; p=0.001$, paired Student's $t$ test; Fig. $6 D, E)$. In recordings from wild-type rats $(N=6$ rats), NAB-14 $(10 \mu \mathrm{M})$ was preapplied (10 min before recording), then CCK INs were recorded. The baseline EPSPs in the presence of NAB-14 had an average amplitude of $6.5 \pm 3.4 \mathrm{mV}$, which was not different from that of control EPSPs $(r=0.05,1.1 ; \mathrm{Cl},-1.9,4.1$; $p=0.45$, unpaired Student's $t$ test). Following the same induction as for control recordings, in the presence of NAB14 , little to no potentiation of the EPSP amplitude $(6 \pm 37 \%$ increase) was observed at $25 \mathrm{~min}$ after tetanization $(r=0.004,0.14 ; \mathrm{Cl},-2.2,2.5 ; p=0.89$, paired Student's $t$ test; Fig. $6 D, E$ ), which was markedly lower than the potentiation observed in control recordings $(r=$ $0.46,-57.7 ; \mathrm{Cl},-95.0,-20.3 ; p=0.005$, unpaired Student's $t$ test). To confirm that LTP in CCK INs was independent of GluN2A, we performed the same recordings in GluN2A-null rats. Following the same induction paradigm, we observed sustained synaptic potentiation in CCK INs from the GluN2Anull rat, with a $134 \pm 98 \%$ increase in EPSP amplitude under control conditions $(N=8$ rats; $r=0.53,7.4 ; \mathrm{Cl}, 1.1,13.6$; $p=0.008$, Wilcoxon test; Fig. $6 F, G)$. Contrary to LTP being reduced in the absence of GluN2A, the magnitude of EPSP potentiation was $48 \%$ greater in CCK INs of the GluN2A-null rat $(r=0.25,76.0 ; \mathrm{Cl}, 3.1,149.0 ; p=0.042$, unpaired Student's $t$ test). In the presence of NAB-14, there was no potentiation of the EPSP when measured at $25 \mathrm{~min}$ in CCK INs from the GluN2A-null rats $(N=6$ rats; $36 \pm 46 \% ; r=0.092,-0.56 ; \mathrm{Cl}$, $-2.6,1.5 ; p=0.51$, paired Student's $t$ test; Fig. $6 F, G)$. These data reveal that LTP at Schaffer collateral synapses onto 
A
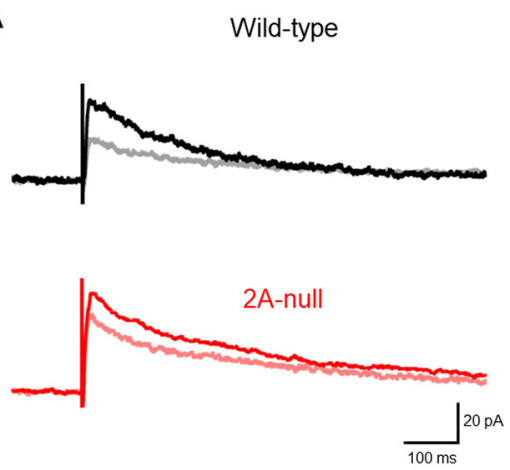

B

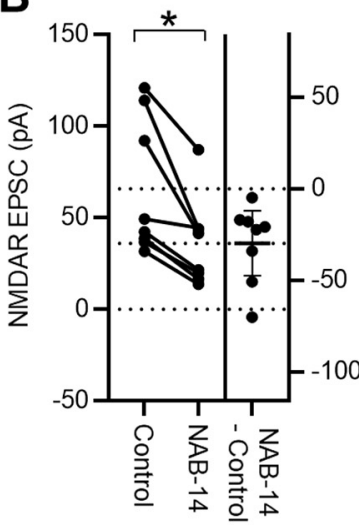

C

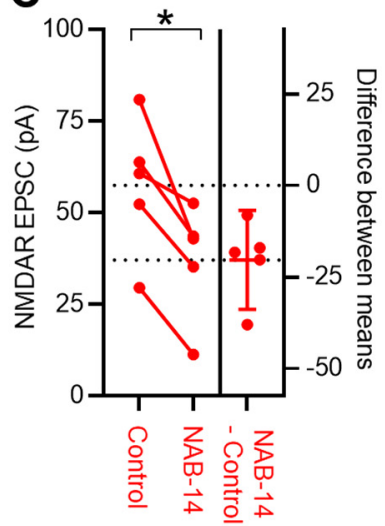

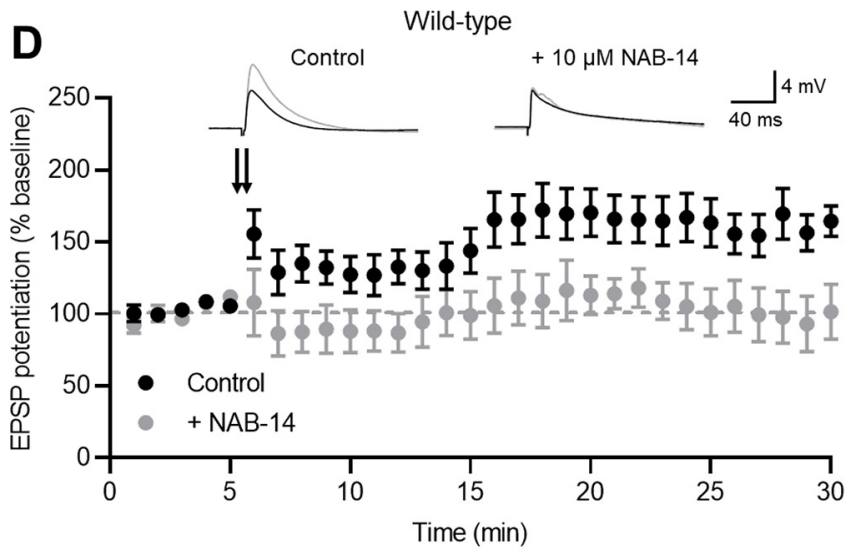

$\mathbf{F}$

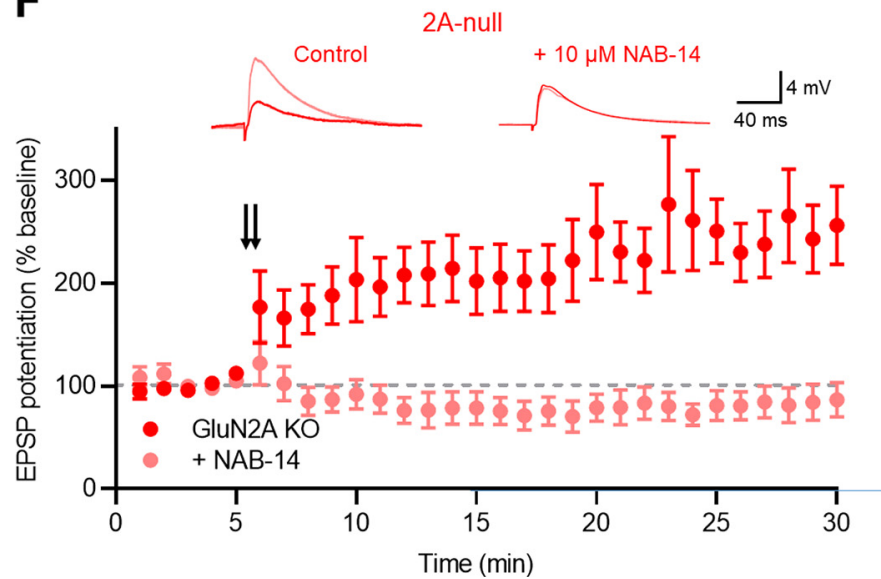

E

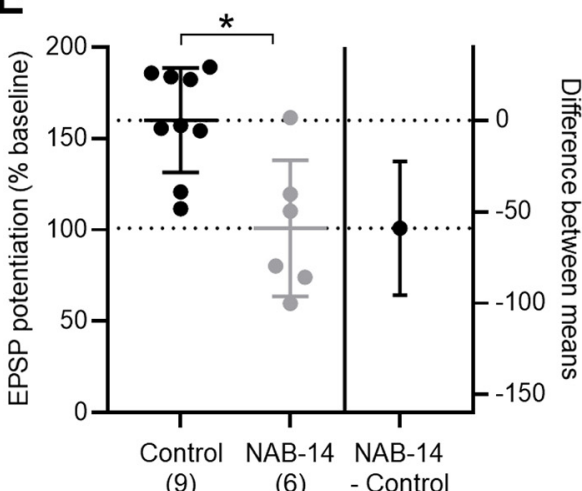

G

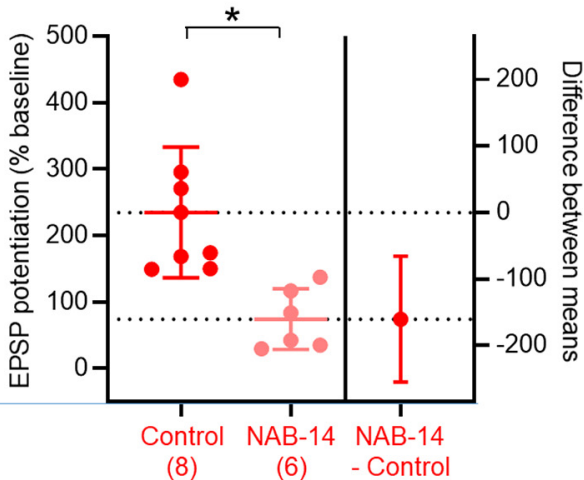

Figure 6. NMDAR-EPSCs in CCK INs are mediated by GluN2D, which is required for LTP induction. $\boldsymbol{A}$, Representative NMDARmediated EPSCs recorded in CCK INs at $+40 \mathrm{mV}$ in the presence of CNQX at (black and red traces) or following 10 min wash-in of the GluN2D-negative allosteric modulator NAB-14 (10 $\mu \mathrm{m}$; gray and pink traces). B, Plot of NMDAR-EPSC amplitudes before and after NAB-14 application in CCK INs. C, Quantification of NMDAR-EPSC amplitudes in CCK INs from GluN2A-null rats before and after NAB-14 application. $\boldsymbol{D}$, Time course of EPSP amplitude in CCK INs from wild-type rats measured from $-70 \mathrm{mV}$ current clamp, following $2 \times 100 \mathrm{~Hz}$ stimulation (double arrow) measured under control conditions (black circles) and in the presence of $10 \mu \mathrm{M}$ NAB14 (gray circles). Representative traces are shown above the chart, showing EPSP at baseline (black traces) and 25 min after LTP induction (gray traces). E, Quantification of LTP, reported as the percentage change in EPSP amplitude from baseline (dashed line) for wild-type CCK INs. Control LTP recordings (black circles; $n=9$ cells; $N=7$ rats) and those performed in the presence of $10 \mu \mathrm{M}$ NAB-14 (gray circles; $n=5$ cells; $N=5$ rats) are shown. The number of tested rats is shown in parentheses. $\boldsymbol{F}$, LTP induction in CCK INs from GluN2A-null rats according to the same scheme as in $\boldsymbol{D}$. Data are shown for control recordings (red circles) and in the presence of NAB-14 (pink circles). Traces of each treatment are above the chart showing data at baseline (red) and after LTP induction (pink traces). G, Quantification of LTP induction in GluN2A-null rats under control (red; $n=6$ cells; $N=5$ rats) and in the presence of NAB-14 (pink; $n=5$ cells; $N=4$ rats). Data are shown as the mean \pm SD. ${ }^{*} p<0.05$, from paired $(\boldsymbol{B})$ and unpaired $(\boldsymbol{D}, \boldsymbol{F})$ Student's $t$ tests. 
CCK INs in part depend on GluN2D-containing NMDARs, but not GluN2A-containing NMDARs.

\section{Discussion}

In the current study, we provide evidence for GluN2Aspecific modulation of synaptic NMDAR-mediated currents in hippocampal INs and PyrCs. We show that NMDAR-EPSCs in PV INs closely resemble those of CA1 PyrCs, in terms of kinetics, synaptic contribution, and GluN2A/2B composition. The closely related SSt IN cell type displays NMDAR-EPSCs that are typically faster and likely composed largely of GluN1/2A or GluN1/2A/2B receptors. Finally, we show unequivocally that CCK INs lack a prominent GluN2A component to their NMDAR-EPSCs; rather, their synaptic NMDARs are likely composed of GluN1/2B/2D triheteromeric receptors based on ifenprodil and NAB-14 sensitivity. Finally, we confirm that these NMDARs in CCK INs are required to induce a Hebbian form of LTP. Together, the data we present provide further evidence that different IN subtypes display divergent synaptic NMDAR pharmacology.

\section{Functional identification of GluN2 subunits in hippocampal neurons}

CA1 PyrCs have been postulated to express both GluN2A/B triheteromeric receptors and GluN2A or GluN2B diheteromeric receptors in mature neurons (AlHallaq et al., 2007; Traynelis et al., 2010; Gray et al., 2011; Tovar et al., 2013). In this study, we provide evidence that CA1 PyrCs likely express at least both GluN2B diheteromeric and GluN2A/B triheteromeric receptors at functional synapses in late juvenile rats. NMDAR-mediated EPSCs were significantly slowed in both rise and decay phase following the loss of GluN2A subunits, but did not have altered amplitudes. The observed $50-60 \%$ block produced by ifenprodil in wild-type PyrCs is consistent with the pharmacology of GluN1/2A/2B triheteromeric NMDARs observed in both heterologous cell lines (Erreger et al., 2005; Hatton and Paoletti, 2005; Marwick et al., 2019) and also in cultured dissociated neurons (Martel et al., 2009; McKay et al., 2012). Indeed, the increased block observed in the GluN2A-null rat is consistent with a switch to GluN1/2B diheteromeric receptors at synapses (Gray et al., 2011; McKay et al., 2012). Nevertheless, ifenprodil has been suggested to block GluN2A-containing receptors to some degree in cultured neurons (Kew et al., 1998; Williams, 2001); however, the $\mathrm{IC}_{50}$ in NMDARs comprising only the Glu2A receptor is an order of magnitude higher than we used in this study (Avenet et al., 1996). Indeed, the ifenprodil block we observe is greater in the absence of GluN2A, consistent with a selective effect at GluN2Bcontaining NMDARs. Furthermore, a range of ifenprodil concentrations up to and including $10 \mu \mathrm{m}$ have been used in ex vivo slice preparations, with overall findings consistent with GluN2B selective effects (Lei and McBain, 2002; Matta et al., 2013). Together, these data show in late juvenile rats that synaptic NMDA receptors are likely composed of a combination of GluN2A/B triheteromeric and GluN2B diheteromeric receptors, which accounts for the slower kinetics and tendency toward reduced NMDAR/AMPAR ratios at Schaffer collateral synapses in these neurons.

The role of NMDARs in the signaling, plasticity, and excitability of hippocampal INs is poorly understood, and that of the contribution of different NMDAR subunits to these functional properties even less so (Moreau and Kullmann, 2013; Akgül and McBain, 2016; Booker and Wyllie, 2021). Many studies have suggested that PV INs likely possess NMDAR-mediated EPSCs with approximately four-fold lower amplitudes compared with AMPAR-mediated EPSCs (Koh et al., 1995; Korotkova et al., 2010; Matta et al., 2013). In the neocortex, such NMDAR-EPSCs possess a GluN2A component in the neocortex (Picard et al., 2019) and display a low GluN2B content in the hippocampus of juvenile mice (Matta et al., 2013). We show that CA1 PV INs possess NMDARs of similar composition to those in CA1 PyrCs based on recordings in the GluN2A-null rat and in the presence of ifenprodil. These NMDAR-EPSCs have faster kinetic properties than neighboring CA1 PyrCs (Gray et al., 2011; see also current data), which in the absence of reduced synaptic amplitudes in the GluN2A-null rat may relate to the altered dendritic properties of PV INs compared with CA1 PyrCs (Nörenberg et al., 2010) or altered NMDA effects on such (Camiré and Topolnik, 2014). Our finding that the amplitude of NMDARs-EPSCs in PV INs is comparable to that of CA1 PyrCs, with similar effects of GluN2A loss and GluN2B blockade, offers an explanation for the presence of readily inducible Hebbian or antiHebbian LTP in the PV and SSt IN classes, reliant on the presence of NMDARs or calcium-permeable AMPARs, respectively (Laezza et al., 1999; Perez et al., 2001; Lamsa et al., 2005; Kullmann and Lamsa, 2007; Szabo et al., 2012; Billingslea et al., 2014). Indeed, activating these NMDARs likely recruits signaling cascades similar to those in PyrCs (Berberich et al., 2005; Gray et al., 2011), with a defined role in plasticity induction (Camiré and Topolnik, 2014). Our data suggest that, in rats, NMDAREPSCs may be mediated by a greater proportion of GluN2B-containing receptors than in mice, given the differential ifenprodil sensitivity observed (Matta et al., 2013), although this has some potential caveats (see above). The presence of large NMDAR-EPSCs, which are similar to CA1 PyrC synaptic NMDARs, may indicate that NMDARs underpin similar roles in terms of dendritic integration in PV INs (Branco et al., 2010; Cornford et al., 2019). While SSt INs share a common developmental origin with PV INs (Tricoire et al., 2011; Chittajallu et al., 2013) and also coexpress PV (Jinno and Kosaka, 2000; Booker et al., 2018), our data indicate that through their differentiation they express functional NMDAR-EPSCs that are distinct from those of PyrCs and other PV IN morphotypes. While the single-channel conductance of NMDARs in OLM cells is similar to that of CA1 PyrCs (Hájos et al., 2002) and their dendritic filtering is rapid (Martina et al., 2000) and similar to that in PV INs (Nörenberg et al., 2010), our data indicate there are fundamental differences in the relative contribution of NMDAR subunits to EPSCs in these cells. In particular, it is 
plausible that SSt INs possess a more uniform population of GluN2A/2B triheteromeric receptors, first because of the $\sim 30 \%$ block with ifenprodil (Hansen et al., 2014) and the longer decay kinetics of NMDAR-EPSCs we observe in the GluN2A-null rats. It has been shown in mice that GluN2D is expressed in PV and SSt INs in adult mice (Standaert et al., 1996; Engelhardt et al., 2015); however, given the rapid kinetics and high sensitivity of NMDAREPSCs to GluN2A loss and ifenprodil, our data suggest that this NMDAR subunit may not contribute to synaptic currents in older rats. Indeed, it is plausible that GluN2D is expressed in rat neurons but may contribute to nonsynaptic mechanisms. As LTP in putative SSt INs is dependent on NMDARs (Ouardouz and Lacaille, 1995), these receptors likely fulfill the typical role of NMDARs in LTP induction (Berberich et al., 2005) in this fundamental feedback interneuron subtype. One major consideration to the function of NMDARs in INs is that GluN2A subunits undergo a developmental increase in expression in PyrCs and INs alike (Flint et al., 1997; Martel et al., 2009; McKay et al., 2012; Matta et al., 2013; Wyllie et al., 2013). How this contributes to the circuit recruitment of INs has not been fully explored other than in a few IN subtypes (Matta et al., 2013). Indeed, whether or not GluN2D subunits undergo such a developmental trajectory in hippocampal INs, or indeed whether GluN2A subunits possess a delayed maturation in CCK INs remains unexplored.

We observed NMDAR-mediated currents in identified CCK IN cell types that were larger and slower than those observed in CA1 PyrCs. This is in good agreement with the presence of GluN2B/2D NMDARs, as described in stratum radiatum INs (Perszyk et al., 2016; Yi et al., 2019) and in GluN2D-containing receptors more generally (Wyllie et al., 1996; Misra et al., 2000; Jones and Gibb, 2005; Logan et al., 2007; Brothwell et al., 2008). The sensitivity of NMDAR-EPSCs in CCK INs to NAB-14 confirms the presence of GluN2C/D receptor subunits in synaptic receptors, with a reduced sensitivity to ifenprodil (Yi et al., 2019) compared with GluN2A/2B triheteromeric receptors. However, as GluN2C is not present in the hippocampus, the predominant receptor target is likely GluN2Dcontaining NMDARs. The absence of GluN2A-mediated EPSC effects is in good agreement with that in recordings performed in non-identified stratum radiatum INs, where a glycine-sensitive GluN2A antagonist did not alter NMDAR-EPSCs (Yi et al., 2019). Given that LTP was strongly attenuated by NAB-14 and the lack of CPAMPAR-mediated LTP (Szabo et al., 2012) in identified CCK INs, our results support previous findings suggesting a central role of NMDARs in synaptic plasticity in these INs (Lamsa et al., 2007). Similarly, as LTP was readily induced in CCK-INs, we confirm previous work showing that GluN2D-containing NMDARs aid this induction (Hrabetova et al., 2000). Together, these data support the idea that GluN2A-containing NMDARs are not required for the induction of LTP in CCK INs (Berberich et al., 2005), but rather it is GluN2D-containing NMDARs that contribute to LTP expression.

Overall, our data extend the previous findings of the study by Perszyk et al. (2016), in which the reported
mRNA corresponding to GluN2A, GluN2B, and GluN2D was abundant in each of the neurochemical cell types we have assessed. For example, this study shows that GluN2A receptor subunits do not appear to contribute to synaptic NMDAR-mediated currents in CCK-INs. While our data do not preclude the possibility that other NMDAR subtypes exist in all of the neuron classes tested, they indicate that such roles would be confined to other (nonsynaptic or non-ionotropic) functions, such as extrasynaptic modulation of plasticity (Ivanov et al., 2006), metabotropic modulation of inhibitory receptors (Chalifoux and Carter, 2010; Guetg et al., 2010), or mediating tonic excitation (Hanson et al., 2019). Furthermore, as we have only examined the major synaptic inputs to different classes of CA1 PyrCs and INs, synapse-specific effects of receptor composition may exist (Arrigoni and Greene, 2004; von Engelhardt et al., 2008). Indeed, recent data suggest that cell type-specific inputs may lead to withincell differences in synaptic composition of NMDARs (Lei and McBain, 2002). Our data suggest that most synaptic NMDARs contain a mixed contribution of receptor subtypes, which provides the tantalizing prospect that synapse and extrasynaptic heterogeneity of NMDARs exists to give rise to functional divergence. The data we present suggest that further work is required to disentangle the contributions of different NMDAR subtypes to synaptic and extrasynaptic functions in hippocampal INs.

\section{Functional ramifications}

Given the large heterogeneity in GluN2 subunit-specific effects on NMDAR-EPSCs in hippocampal INs, there is a wide variety of potential ramifications for human disease. First, given that GluN2A subunits contribute significantly to PV and SSt IN synaptic NMDARs, this heterogeneity emphasizes the need to further elucidate the role of these neurons in epileptic syndromes, as the GluN2A subunit may be a critical determinant of some forms of epilepsy (Marwick et al., 2019). Furthermore, as GluN2D de novo mutations have also been linked to epileptic encephalopathies (Li et al., 2016; Camp and Yuan, 2020), and given the clear role of this subunit in CCK IN synaptic function, the heterogeneity may explain the selective loss of these neurons in some forms of experimental epilepsy (Wyeth et al., 2010; Sun et al., 2014). These data suggest potential therapeutic avenues by which NMDAR function is selectively modulated in a brain region and in a cell type-specific manner. Furthermore, NMDARs contribute to the spike coupling of INs to ongoing synaptic activity (Matta et al., 2013). How divergent NMDAR kinetic properties between different IN subtypes contribute to ongoing circuit activity remains unknown, but will likely have direct ramifications for local information processing.

In summary, we provide clear evidence for GluN2A, GluN2B, and GluN2D subunit-containing NMDARs in neurochemically and morphologically defined INs and PyrCs of the rat. These findings provide insight into the mechanisms of synaptic plasticity generation in CCK INs, which rely on GluN2B- and GluN2D-containing, but not GluN2A-containing, NMDARs. These data are important 
to our understanding of how different IN classes integrate synaptic information.

\section{References}

Akgül G, McBain CJ (2016) Diverse roles for ionotropic glutamate receptors on inhibitory interneurons in developing and adult brain. $\mathrm{J}$ Physiol 594:5471-5490.

Al-Hallaq RA, Conrads TP, Veenstra TD, Wenthold RJ (2007) NMDA di-heteromeric receptor populations and associated proteins in rat hippocampus. J Neurosci 27:8334-8343.

Antoine MW, Langberg T, Schnepel P, Feldman DE (2019) Increased excitation-inhibition ratio stabilizes synapse and circuit excitability in four autism mouse models. Neuron 101:648-661.e4.

Arrigoni E, Greene RW (2004) Schaffer collateral and perforant path inputs activate different subtypes of NMDA receptors on the same CA1 pyramidal cell. Br J Pharmacol 142:317-322.

Avenet P, Léonardon J, Besnard F, Graham D, Frost J, Depoortere H, Langer SZ, Scatton B (1996) Antagonist properties of the stereoisomers of ifenprodil at NR1A/NR2A and NR1A/NR2B subtypes of the NMDA receptor expressed in Xenopus oocytes. Eur $\mathrm{J}$ Pharmacol 296:209-213.

Berberich S, Punnakkal P, Jensen V, Pawlak V, Seeburg PH, Hvalby $\varnothing$, Köhr G (2005) Lack of NMDA receptor subtype selectivity for hippocampal long-term potentiation. J Neurosci 25:6907-6910.

Billingslea EN, Tatard-Leitman VM, Anguiano J, Jutzeler CR, Suh J, Saunders JA, Morita S, Featherstone RE, Ortinski PI, Gandal MJ, Lin R, Liang Y, Gur RE, Carlson GC, Hahn C-G, Siegel SJ (2014) Parvalbumin cell ablation of NMDA-R1 causes increased resting network excitability with associated social and self-care deficits. Neuropsychopharmacology 39:1603-1613.

Blasco-lbáñez JM, Freund TF (1995) Synaptic input of horizontal interneurons in stratum oriens of the hippocampal CA1 subfield: structural basis of feed-back activation. Eur J Neurosci 7:21702180.

Booker SA, Campbell GR, Mysiak KS, Brophy PJ, Kind PC, Mahad DJ, Wyllie DJA (2017) Loss of protohaem IX farnesyltransferase in mature dentate granule cells impairs short-term facilitation at mossy fibre to CA3 pyramidal cell synapses. J Physiol 595:21472160.

Booker SA, Song J, Vida I (2014) Whole-cell patch-clamp recordings from morphologically- and neurochemically-identified hippocampal interneurons. J Vis Exp. Advance online publication. Retrieved Sep 30 2014. doi: 10.3791/51706.

Booker SA, Vida I (2018) Morphological diversity and connectivity of hippocampal interneurons. Cell Tissue Res 373:619-641.

Booker SA, Wyllie DJ (2021) NMDA receptor function in inhibitory neurons. Neuropharmacology 108609.

Booker SA, Althof D, Gross A, Loreth D, Müller J, Unger A, Fakler B, Varro A, Watanabe M, Gassmann M, Bettler B, Shigemoto R, Vida I, Kulik Á (2017) KCTD12 auxiliary proteins modulate kinetics of GABAB receptor-mediated inhibition in cholecystokinin-containing interneurons. Cereb Cortex 27:2318-2334.

Booker SA, Loreth D, Gee AL, Watanabe M, Kind PC, Wyllie DJ, Kulik A, Vida I (2018) Postsynaptic GABABRs inhibit L-type calcium channels and abolish long-term potentiation in hippocampal somatostatin interneurons. Cell Rep 22:36-43.

Branco T, Clark BA, Häusser M (2010) Dendritic discrimination of temporal input sequences in cortical neurons. Science 329:16711675.

Brothwell SL, Barber JL, Monaghan DT, Jane DE, Gibb AJ, Jones S (2008) NR2B- and NR2D-containing synaptic NMDA receptors in developing rat substantia nigra pars compacta dopaminergic neurones. J Physiol 586:739-750.

Camiré O, Topolnik L (2014) Dendritic calcium nonlinearities switch the direction of synaptic plasticity in fast-spiking interneurons. $\mathrm{J}$ Neurosci 34:3864-3877.
Camp CR, Yuan H (2020) GRIN2D/GluN2D NMDA receptor: unique features and its contribution to pediatric developmental and epileptic encephalopathy. Eur J Paediatr Neurol 24:89-99.

Chalifoux JR, Carter AG (2010) GABAB receptors modulate NMDA receptor calcium signals in dendritic spines. Neuron 66:101-113.

Chittajallu R, Craig MT, McFarland A, Yuan X, Gerfen S, Tricoire L, Erkkila B, Barron SC, Lopez CM, Liang BJ, Jeffries BW, Pelkey KA, McBain CJ (2013) Dual origins of functionally distinct O-LM interneurons revealed by differential 5-HT 3A R expression. Nat Neurosci 16:1598-1607.

Chittajallu R, Wester JC, Craig MT, Barksdale E, Yuan XQ, Akgül G, Fang C, Collins D, Hunt S, Pelkey KA, McBain CJ (2017) Afferent specific role of NMDA receptors for the circuit integration of hippocampal neurogliaform cells. Nat Commun 8:152.

Cornford JH, Mercier MS, Leite M, Magloire V, Häusser M, Kullmann DM (2019) Dendritic NMDA receptors in parvalbumin neurons enable strong and stable neuronal assemblies. eLife 8:e49872.

Cull-Candy S, Brickley S, Farrant M (2001) NMDA receptor subunits: diversity, development and disease. Curr Opin Neurobiol 11:327335.

Czéh B, Varga ZKK, Henningsen K, Kovács GL, Miseta A, Wiborg O (2015) Chronic stress reduces the number of GABAergic interneurons in the adult rat hippocampus, dorsal-ventral and region-specific differences. Hippocampus 25:393-405.

Daskalakis ZJ, Christensen BK, Chen R, Fitzgerald PB, Zipursky RB, Kapur S (2002) Evidence for impaired cortical inhibition in schizophrenia using transcranial magnetic stimulation. Arch Gen Psychiatry 59:347-354.

Engelhardt Jv, Bocklisch C, Tönges L, Herb A, Mishina M, Monyer H (2015) GluN2D-containing NMDA receptors-mediate synaptic currents in hippocampal interneurons and pyramidal cells in juvenile mice. Front Cell Neurosci 9:95.

Erreger K, Dravid SM, Banke TG, Wyllie DJ, Traynelis SF (2005) Subunit-specific gating controls rat NR1/NR2A and NR1/NR2B NMDA channel kinetics and synaptic signalling profiles. J Physiol 563:345-358.

Flint AC, Maisch US, Weishaupt JH, Kriegstein AR, Monyer H (1997) NR2A subunit expression shortens NMDA receptor synaptic currents in developing neocortex. J Neurosci 17:2469-2476.

Garst-Orozco J, Malik R, Lanz TA, Weber ML, Xi H, Arion D, Enwright JF, Lewis DA, O'Donnell P, Sohal VS, Buhl DL (2020) GluN2Dmediated excitatory drive onto medial prefrontal cortical PV + fastspiking inhibitory interneurons. PLoS One 15:e0233895.

Gielen M, Retchless BS, Mony L, Johnson JW, Paoletti P (2009) Mechanism of differential control of NMDA receptor activity by NR2 subunits. Nature 459:703-707.

Gray JA, Shi Y, Usui H, During MJ, Sakimura K, Nicoll RA (2011) Distinct modes of AMPA receptor suppression at developing synapses by GluN2A and GluN2B: single-cell NMDA receptor subunit deletion in vivo. Neuron 71:1085-1101.

Guetg N, Abdel Aziz S, Holbro N, Turecek R, Rose T, Seddik R, Gassmann M, Moes S, Jenoe P, Oertner TG, Casanova E, Bettler B (2010) NMDA receptor-dependent GABAB receptor internalization via CaMKIl phosphorylation of serine 867 in GABAB1. Proc Natl Acad Sci U S A 107:13924-13929.

Guzman SJ, Schlögl A, Schmidt-Hieber C (2014) Stimfit: quantifying electrophysiological data with Python. Front Neuroinform 8:16.

Hájos N, Freund T, Mody I (2002) Comparison of single NMDA receptor channels recorded on hippocampal principal cells and oriens/ alveus interneurons projecting to stratum lacunosum-moleculare (O-LM cells). Acta Biol Hung 53:465-472.

Hansen KB, Ogden KK, Yuan H, Traynelis SF (2014) Distinct functional and pharmacological properties of triheteromeric GluN1/ GluN2A/GluN2B NMDA receptors. Neuron 81:1084-1096.

Hansen KB, Yi F, Perszyk RE, Furukawa H, Wollmuth LP, Gibb AJ, Traynelis SF (2018) Structure, function, and allosteric modulation of NMDA receptors. J Gen Physiol 150:1081-1105.

Hanson E, Armbruster M, Lau LA, Sommer ME, Klaft Z-J, Swanger SA, Traynelis SF, Moss SJ, Noubary F, Chadchankar J, Dulla CG (2019) Tonic activation of GluN2C/GluN2D-containing NMDA 
receptors by ambient glutamate facilitates cortical interneuron maturation. J Neurosci 39:3611-3626.

Hatton CJ, Paoletti P (2005) Modulation of triheteromeric NMDA receptors by N-terminal domain ligands. Neuron 46:261-274.

Hrabetova S, Serrano P, Blace N, Tse HW, Skifter DA, Jane DE, Monaghan DT, Sacktor TC (2000) Distinct NMDA receptor subpopulations contribute to long-term potentiation and long-term depression induction. J Neurosci 20:RC81-RC81.

Ivanov A, Pellegrino C, Rama S, Dumalska I, Salyha Y, Ben-Ari Y, Medina I (2006) Opposing role of synaptic and extrasynaptic NMDA receptors in regulation of the extracellular signal-regulated kinases (ERK) activity in cultured rat hippocampal neurons. J Physiol 572:789-798.

Jinno S, Kosaka T (2000) Colocalization of parvalbumin and somatostatin-like immunoreactivity in the mouse hippocampus: quantitative analysis with optical disector. J Comp Neurol 428:377-388.

Jones S, Gibb AJ (2005) Functional NR2B- and NR2D-containing NMDA receptor channels in rat substantia nigra dopaminergic neurones. J Physiol 569:209-221.

Kew JN, Richards JG, Mutel V, Kemp JA (1998) Developmental changes in NMDA receptor glycine affinity and ifenprodil sensitivity reveal three distinct populations of NMDA receptors in individual rat cortical neurons. J Neurosci 18:1935-1943.

Koh DS, Geiger J, Jonas P, Sakmann B (1995) Ca (2+)-permeable AMPA and NMDA receptor channels in basket cells of rat hippocampal dentate gyrus. J Physiol 485:383-402.

Korotkova T, Fuchs EC, Ponomarenko A, von Engelhardt J, Monyer H (2010) NMDA receptor ablation on parvalbumin-positive interneurons impairs hippocampal synchrony, spatial representations, and working memory. Neuron 68:557-569.

Kotzadimitriou D, Nissen W, Paizs M, Newton K, Harrison PJ, Paulsen O, Lamsa K (2018) Neuregulin 1 type I overexpression is associated with reduced NMDA receptor-mediated synaptic signaling in hippocampal interneurons expressing PV or CCK. eNeuro 5:ENEURO.0418-17.2018.

Kullmann DM, Lamsa KP (2007) Long-term synaptic plasticity in hippocampal interneurons. Nat Rev Neurosci 8:687-699.

Laezza F, Doherty JJ, Dingledine R (1999) Long-term depression in hippocampal interneurons: joint requirement for pre-and postsynaptic events. Science 285:1411-1414.

Lamsa K, Heeroma JH, Kullmann DM (2005) Hebbian LTP in feedforward inhibitory interneurons and the temporal fidelity of input discrimination. Nat Neurosci 8:916-924.

Lamsa K, Irvine EE, Giese KP, Kullmann DM (2007) NMDA receptordependent long-term potentiation in mouse hippocampal interneurons shows a unique dependence on $\mathrm{Ca}^{2+} /$ calmodulin-dependent kinases. J Physiol 584:885-894.

Lei S, McBain CJ (2002) Distinct NMDA receptors provide differential modes of transmission at mossy fiber-interneuron synapses. Neuron 33:921-933.

Li D, Yuan H, Ortiz-Gonzalez XR, Marsh ED, Tian L, McCormick EM, Kosobucki GJ, Chen W, Schulien AJ, Chiavacci R, Tankovic A, Naase C, Brueckner $F$, von Stülpnagel-Steinbeis $C, \mathrm{Hu} \mathrm{C}$, Kusumoto H, Hedrich UBS, Elsen G, Hörtnagel K, Aizenman E, et al. (2016) GRIN2D recurrent de novo dominant mutation causes a severe epileptic encephalopathy treatable with NMDA receptor channel blockers. Am J Hum Genet 99:802-816.

Liu L, Wong TP, Pozza MF, Lingenhoehl K, Wang Y, Sheng M, Auberson YP, Wang YT (2004) Role of NMDA receptor subtypes in governing the direction of hippocampal synaptic plasticity. Science 304:1021-1024.

Logan SM, Partridge JG, Matta JA, Buonanno A, Vicini S (2007) Long-lasting NMDA receptor-mediated EPSCs in mouse striatal medium spiny neurons. J Neurophysiol 98:2693-2704.

Longair MH, Baker DA, Armstrong JD (2011) Simple Neurite Tracer: open source software for reconstruction, visualization and analysis of neuronal processes. Bioinformatics 27:2453-2454.

Malenka RC (1991) Postsynaptic factors control the duration of synaptic enhancement in area CA1 of the hippocampus. Neuron 6:53-60.
Manouze H, Ghestem A, Poillerat V, Bennis M, Ba-M'hamed S, Benoliel JJ, Becker C, Bernard C (2019) Effects of single cage housing on stress, cognitive, and seizure parameters in the rat and mouse pilocarpine models of epilepsy. eNeuro 6:ENEURO.017918.2019.

Martel M-A, Wyllie DJ, Hardingham GE (2009) In developing hippocampal neurons, NR2B-containing NMDA receptors can mediate signalling to neuronal survival and synaptic potentiation, as well as neuronal death. Neuroscience 158:334-343.

Martina M, Vida I, Jonas P (2000) Distal initiation and active propagation of action potentials in interneuron dendrites. Science 287:295-300.

Marwick KF, Hansen KB, Skehel PA, Hardingham GE, Wyllie DJ (2019) Functional assessment of triheteromeric NMDA receptors containing a human variant associated with epilepsy. J Physiol 597:1691-1704.

Matta JA, Pelkey KA, Craig MT, Chittajallu R, Jeffries BW, McBain CJ (2013) Developmental origin dictates interneuron AMPA and NMDA receptor subunit composition and plasticity. Nat Neurosci 16:1032-1041.

McKay S, Griffiths N, Butters P, Thubron E, Hardingham G, Wyllie D (2012) Direct pharmacological monitoring of the developmental switch in NMDA receptor subunit composition using TCN 213, a GluN2A-selective, glycine-dependent antagonist. Br J Pharmacol 166:924-937.

Misra C, Brickley SG, Wyllie DJ, Cull-Candy SG (2000) Slow deactivation kinetics of NMDA receptors containing NR1 and NR2D subunits in rat cerebellar Purkinje cells. J Physiol 525 Pt 2:299-305.

Monyer H, Burnashev N, Laurie DJ, Sakmann B, Seeburg PH (1994) Developmental and regional expression in the rat brain and functional properties of four NMDA receptors. Neuron 12:529-540.

Moreau AW, Kullmann DM (2013) NMDA receptor-dependent function and plasticity in inhibitory circuits. Neuropharmacology 74:23-31.

Morris RG (2013) NMDA receptors and memory encoding. Neuropharmacology 74:32-40.

Morris RGM, Davis S, Butcher S (1990) Hippocampal synaptic plasticity and NMDA receptors: a role in information storage? Philos Trans R Soc Lond B Biol Sci 329:187-204.

Nörenberg A, Hu H, Vida I, Bartos M, Jonas P (2010) Distinct nonuniform cable properties optimize rapid and efficient activation of fast-spiking GABAergic interneurons. Proc Natl Acad Sci U S A 107:894-899.

Ouardouz M, Lacaille J-C (1995) Mechanisms of selective long-term potentiation of excitatory synapses in stratum oriens/alveus interneurons of rat hippocampal slices. J Neurophysiol 73:810-819.

Pelkey KA, Chittajallu R, Craig MT, Tricoire L, Wester JC, McBain CJ (2017) Hippocampal GABAergic inhibitory interneurons. Physiol Rev 97:1619-1747.

Perez Y, Morin F, Lacaille J-C (2001) A hebbian form of long-term potentiation dependent on mGluR1a in hippocampal inhibitory interneurons. Proc Natl Acad Sci U S A 98:9401-9406.

Perszyk RE, DiRaddo JO, Strong KL, Low C-M, Ogden KK, Khatri A, Vargish GA, Pelkey KA, Tricoire L, Liotta DC, Smith Y, McBain CJ, Traynelis SF (2016) GluN2D-containing N-methyl-d-aspartate receptors mediate synaptic transmission in hippocampal interneurons and regulate interneuron activity. Mol Pharmacol 90:689-702.

Picard N, Takesian AE, Fagiolini M, Hensch TK (2019) NMDA 2A receptors in parvalbumin cells mediate sex-specific rapid ketamine response on cortical activity. Mol Psychiatry 24:828-838.

Seeburg PH, Burnashev N, Köhr G, Kuner T, Sprengel R, Monyer H (1995) The NMDA receptor channel: molecular design of a coincidence detector. In: Proceedings of the 1993 Laurentian Hormone Conference (Bardin CW, ed), pp 19-34. San Diego: Academic.

Sloviter RS (1987) Decreased hippocampal inhibition and a selective loss of interneurons in experimental epilepsy. Science 235:73-76.

Standaert DG, Landwehrmeyer GB, Kerner JA, Penney JB, Young $A B$ (1996) Expression of NMDAR2D glutamate receptor subunit mRNA in neurochemically identified interneurons in the rat 
neostriatum, neocortex and hippocampus. Brain Res Mol Brain Res 42:89-102.

Strehlow V, Heyne HO, Vlaskamp DRM, Marwick KFM, Rudolf G, de Bellescize J, Biskup S, Brilstra EH, Brouwer OF, Callenbach PMC, Hentschel J, Hirsch E, Kind PC, Mignot C, Platzer K, Rump P, Skehel PA, Wyllie DJA, GRIN2A study group, Hardingham GE, et al. (2020) Genotype-phenotype correlation of 247 individuals with GRIN2A-related disorders identifies two distinct phenotypic subgroups associated with different classes of variants, protein domains and functional consequences. Brain 142:80-92.

Stern P, Béhé P, Schoepfer R, Colquhoun D (1992) Single-channel conductances of NMDA receptors expressed from cloned cDNAs: comparison with native receptors. Proc R Soc Lond B Biol Sci 250:271-277.

Sun C, Sun J, Erisir A, Kapur J (2014) Loss of cholecystokinin-containing terminals in temporal lobe epilepsy. Neurobiol Dis 62:4455.

Swanger SA, Vance KM, Acker TM, Zimmerman SS, DiRaddo JO, Myers SJ, Bundgaard C, Mosley CA, Summer SL, Menaldino DS, Jensen HS, Liotta DC, Traynelis SF (2018) A novel negative allosteric modulator selective for GluN2C/2D-containing NMDA receptors inhibits synaptic transmission in hippocampal interneurons. ACS Chem Neurosci 9:306-319.

Szabo A, Somogyi J, Cauli B, Lambolez B, Somogyi P, Lamsa KP (2012) Calcium-permeable AMPA receptors provide a common mechanism for LTP in glutamatergic synapses of distinct hippocampal interneuron types. J Neurosci 32:6511-6516.

Tovar KR, McGinley MJ, Westbrook GL (2013) Triheteromeric NMDA receptors at hippocampal synapses. J Neurosci 33:9150-9160.

Tozzi A, de lure A, Bagetta V, Tantucci M, Durante V, Quiroga-Varela A, Costa C, Di Filippo M, Ghiglieri V, Latagliata EC, Wegrzynowicz M, Decressac M, Giampà C, Dalley JW, Xia J, Gardoni F, Mellone M, El-Agnaf OM, Ardah MT, Puglisi-Allegra S, et al. (2016) Alphasynuclein produces early behavioral alterations via striatal cholinergic synaptic dysfunction by interacting with GluN2D N-methylD-aspartate receptor subunit. Biol Psychiatry 79:402-414.

Traynelis SF, Wollmuth LP, McBain CJ, Menniti FS, Vance KM, Ogden KK, Hansen KB, Yuan H, Myers SJ, Dingledine R (2010) Glutamate receptor ion channels: structure, regulation, and function. Pharmacol Rev 62:405-496.
Tricoire L, Pelkey KA, Erkkila BE, Jeffries BW, Yuan X, McBain CJ (2011) A blueprint for the spatiotemporal origins of mouse hippocampal interneuron diversity. J Neurosci 31:10948-10970.

Tsien JZ, Huerta PT, Tonegawa S (1996) The essential role of hippocampal CA1 NMDA receptor-dependent synaptic plasticity in spatial memory. Cell 87:1327-1338.

Vicini S, Wang JF, Li JH, Zhu WJ, Wang YH, Luo JH, Wolfe BB, Grayson DR (1998) Functional and pharmacological differences between recombinant N-methyl-D-aspartate receptors. J Neurophysiol 79:555566.

Volianskis A, Bannister N, Collett VJ, Irvine MW, Monaghan DT, Fitzjohn SM, Jensen MS, Jane DE, Collingridge GL (2013) Different NMDA receptor subtypes mediate induction of long-term potentiation and two forms of short-term potentiation at CA1 synapses in rat hippocampus in vitro. J Physiol 591:955-972.

von Engelhardt J, Doganci B, Jensen V, Hvalby $\varnothing$, Göngrich C, Taylor A, Barkus C, Sanderson DJ, Rawlins JNP, Seeburg PH, Bannerman DM, Monyer H (2008) Contribution of hippocampal and extra-hippocampal NR2B-containing NMDA receptors to performance on spatial learning tasks. Neuron 60:846-860.

Wenzel A, Fritschy JM, Mohler H, Benke D (1997) NMDA receptor heterogeneity during postnatal development of the rat brain: differential expression of the NR2A, NR2B, and NR2C subunit proteins. J Neurochem 68:469-478.

Williams K (2001) Ifenprodil, a novel NMDA receptor antagonist: site and mechanism of action. Curr Drug Targets 2:285-298.

Wyeth MS, Zhang N, Mody I, Houser CR (2010) Selective reduction of cholecystokinin-positive basket cell innervation in a model of temporal lobe epilepsy. J Neurosci 30:8993-9006.

Wyllie DJ, Béhé P, Nassar M, Schoepfer R (1996) Single-channel currents from recombinant NMDA NRIA/NR2D receptors expressed in Xenopus oocytes. Proc R Soc Lond B Biol Sci 263:1079-1086.

Wyllie DJ, Béhé P, Colquhoun D (1998) Single-channel activations and concentration jumps: comparison of recombinant NR1a/ NR2A and NR1a/NR2D NMDA receptors. J Physiol 510:1-18.

Wyllie DJ, Livesey M, Hardingham G (2013) Influence of GluN2 subunit identity on NMDA receptor function. Neuropharmacology 74 : 4-17.

Yi F, Bhattacharya S, Thompson CM, Traynelis SF, Hansen KB (2019) Functional and pharmacological properties of triheteromeric GluN1/2B/2D NMDA receptors. J Physiol 597:5495-5514. 